\author{
Türküler Özgümüş \\ e-mail: turkulerozgumus@iyte.edu.tr \\ Moghtada Mobedi \\ e-mail: moghtadamobedi@iyte.edu.tr \\ Ünver Özkol \\ e-mail: unverozkol@iyte.edu.tr \\ Mechanical Engineering Department, \\ Izmir Institute of Technology, \\ Urla, 35430 izmir, Turkey
}

\author{
Akira Nakayama \\ Department of Mechanical Engineering, \\ Shizuoka University, \\ 3-5-1 Johoku, 432 Hamamatsu, Japan \\ e-mail: tmanaka@ipc.shizuoka.ac.jp
}

\section{Thermal Dispersion in Porous Media-A Review on the Experimental Studies for Packed Beds}

\begin{abstract}
Thermal dispersion is an important topic in the convective heat transfer in porous media. In order to determine the heat transfer in a packed bed, the effective thermal conductivity including both stagnant and dispersion thermal conductivities should be known. Several theoretical and experimental studies have been performed on the determination of the effective thermal conductivity. The aim of this study is to review the experimental studies done on the determination of the effective thermal conductivity of the packed beds. In this study, firstly brief information on the definition of the thermal dispersion is presented and then the reported experimental studies on the determination of the effective thermal conductivity are summarized and compared. The reported experimental methods are classified into three groups: (1) heat addition/removal at the lateral boundaries, (2) heat addition at the inlet/ outlet boundary, (3) heat addition inside the bed. For each performed study, the experimental details, methods, obtained results, and suggested correlations for the determination of the effective thermal conductivity are presented. The similarities and differences between experimental methods and reported studies are shown by tables. Comparison of the correlations for the effective thermal conductivity is made by using figures and the results of the studies are discussed. [DOI: 10.1115/1.4024351]
\end{abstract}

Keywords: heat transfer, thermal dispersion, porous media, packed bed, effective thermal conductivity, experimental methods

\section{Introduction}

A porous medium is a composite medium containing voids and solid particles. The voids can be interconnected (open cell) or unconnected (closed cell). The applications of heat and fluid flow in porous media are encountered in many industrial areas such as food and crop drying processes, chemical reactors, filters, gas separator adsorbent beds. Water flowing through the rocks and soil can be modeled by using the hydrodynamic equations of fluid flow in porous media. In an open cell porous medium, fluid flows in the pores (or voids) between the particles. The mechanism of the flow through the pores is complex and the flow is threedimensional; hence pore level determination of the velocity and the temperature fields is difficult. For this reason, simplifier approaches are required to overcome the difficulties in analyzing heat and fluid flow in porous media. One of the most common methods is the macroscopic approach in which heat and fluid flow equations are established for a continuum domain involving the whole volume of the porous media-although a discontinuity in the flow field exists due to the solid phase. This requires definitions for the volume averaged velocity, pressure, and temperature including both solid and fluid phases. Taking a volume integral of the continuity, momentum, and energy equations over a control volume in the domain yields the macroscopic governing equations for the continuum domain. The volume average of the heat transfer equation results in two extra terms named as thermal dispersion and thermal tortuosity $[1,2]$.

Thermal dispersion is an important phenomenon in analyzing convective heat transfer in the porous media. In addition to the molecular diffusion, thermal dispersion is a factor affecting the heat transfer. Thermal dispersion is resulted due to the nonuniformity of the pore level temperature and velocity, and the effects

Manuscript received July 12, 2012; final manuscript received April 17, 2013; published online July 15, 2013. Editor: Harry Dankowicz. of hydrodynamic mixing on the temperature field. The mixing of the fluid can be caused by different factors such as

- the obstacles in the porous medium that causes change of fluid flow direction

- recirculation of the fluid elements in the voids where pressure is reduced

- nonuniform accessibility of the fluid elements to the voids

- eddy diffusion when the flow is turbulent

- the dead-end voids of the porous media

As it was mentioned before, the pore level heat transfer analysis for a large volume of porous media is unpractical and difficult This leads researchers to the macroscopic analysis by using the volume averaging method. Even for a simple, unidirectional, fully developed heat and fluid flow in a tube, establishment of the heat and fluid motion equations based on the average velocity and temperature requires an extra dispersion term. The extra dispersion term involves the effects of temperature and velocity non uniformities which is called Taylor dispersion [2].

In order to obtain a general thermal dispersion relation valid for the various porous media, the dimensionless parameters effecting the thermal dispersion should be specified. Our review on the proposed mathematical relations for the determination of the thermal dispersion shows that the following parameters highly influence the thermal dispersion value:

- Peclet and Reynolds numbers: the thermal dispersion value highly depends on the particle-based Reynolds number because the flow patterns and the mixing of the fluid in the voids between the particles are highly influenced by the particle-based Reynolds number. The thermal dispersion increases with increasing Reynolds number. Some suggested correlations for the determination of the effective thermal conductivity values have been developed based on the particle-based Peclet number in order to involve not only the 
hydrodynamic effects but also the thermal interactions in the pore level.

- The ratio of the thermal conductivities between solid and fluid phases $\left(k_{s} / k_{f}\right)$ (or the ratio of the equivalent and the fluid thermal conductivities $\left(k_{e} / k_{f}\right)$ ): the thermal dispersion is affected from the thermal interactions between solid and fluid phases and therefore from their conductivities. Generally, instead of the thermal conductivity ratio of two phases, the ratio of equivalent (stagnant) thermal conductivity of the bed to the fluid phase thermal conductivity $\left(k_{e} / k_{f}\right)$, which also includes $k_{s} / k_{f}$, is added into the correlation.

- Porosity $(\varepsilon)$ : porosity is defined as the ratio of the fluid occupied volume to the total control volume. Although there are correlations which include the effect of porosity explicitly, in the most of them the effect of porosity is hidden. There is no doubt that the thermal dispersion is highly affected from porosity, however its effects are involved by Reynolds number and the equivalent thermal conductivity.

- Porous structure: the porous structure (i.e., void shapes, connection between particles, distance between particles, surface roughness, etc.) plays an important role in the thermal dispersion due to its effect on the pore level flow.

- Ratio of thermal capacitances between solid and fluid phases $\left(\left(\rho c_{p}\right)_{s} /\left(\rho c_{p}\right)_{f}\right)$ [2]: although, there is no correlation in this review which includes this ratio for the determination of the effective thermal conductivity, the ratio might be important in transient heat transfer problems because the amount of stored or released heat directly affects temperature distribution in the porous media.

The influences of some of the above parameters were explained by Kaviany [2]. In this study, after presenting brief information on the mathematical definition of the thermal dispersion, the experimental approaches reported in the literature for the determination of the thermal dispersion are reviewed in three groups as: (1) heat addition/removal at the lateral boundaries, (2) heat addition at the inlet/outlet boundary, and (3) heat addition inside the bed. The experimental studies are categorized based on the heating conditions of the test section in the experimental setups. The principles of each method and the related reported studies are explained by using the schematic views of the experimental setups. In most of the research reviewed in this study, thermal equilibrium assumption was considered for the determination of the effective thermal conductivity. A diagram is prepared to show the range of the Reynolds numbers studied in the literature. The reported studies are compared with each other according to the treatments for the determination of the axial and/or the radial effective thermal conductivities, the boundary conditions of the bed, the materials, and the geometrical parameters of the packing particles, and the shape and the geometrical parameters of the packed bed. A table showing the proposed relations for the determination of the radial and/ or axial thermal dispersion conductivities is also presented.

\section{Background of Thermal Dispersion}

The fluid velocity in the voids between the particles of the porous media is not uniform. The discontinuities in the velocity field exist because of the existence of the solid phase. Furthermore, sudden changes in the temperature field occur because of the heat transport in the interphase boundaries. For a porous medium that contains a solid phase and an incompressible Newtonian fluid without considerable effect of viscous dissipation, the following energy equations for the fluid and the solid phases can be written, respectively.

$$
\begin{gathered}
\rho_{f} c_{p f}\left(\frac{\partial T_{f}}{\partial t}+\nabla \cdot \vec{u} T_{f}\right)=k_{f} \nabla^{2} T_{f} \\
\rho_{s} c_{p s} \frac{\partial T_{s}}{\partial t}=k_{s} \nabla^{2} T_{s}
\end{gathered}
$$

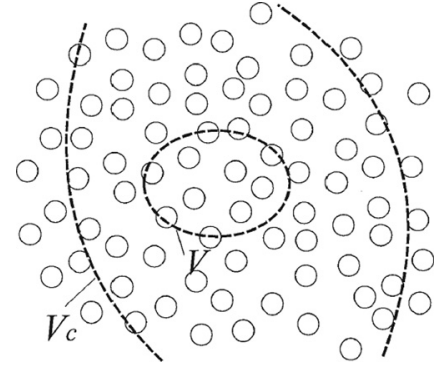

Fig. 1 Microscopic view of the porous structure [1]

where $\rho$ is density, $c_{p}$ is specific heat, and $T$ is temperature. The subscript $s$ refers to the solid while $f$ indicates the fluid flowing through the pores. The velocity vector and the thermal conductivity are shown by $\vec{u}$ and $k$. To obtain the macroscopic energy equations for the fluid and the solid phases of the porous media, the volume averaging approach can be used. Whitaker and his coworkers were studied the volume averaging method in detail and published very valuable studies on the theory of the volume averaging method and its applications for the engineering problems. The detailed explanation can be found in the published book and papers [3-6]. However, brief information on the volume averaging method is given in this section.

A representative control volume of a porous medium is shown in Fig. 1. To obtain a meaningful volume averaged quantity, the characteristic length of the control volume (i.e., $V^{1 / 3}$ ) should be greater than the microscopic characteristic length and also should be smaller than the macroscopic characteristic length (i.e., $V_{C}^{1 / 3}$ ) [1]. In general, the volume averaging of a quantity $\varphi$ is defined by Eq. (3) where $V$ is the total volume of fluid and solid phases in the control volume.

$$
\langle\varphi\rangle=\frac{1}{V} \int_{V} \varphi d V
$$

To separately obtain the intrinsic averaged quantities in the phases, the pore volume averaging is considered for the fluid phase (Eq. (4)) and the particle volume averaging is considered for the solid phase (Eq. (5)) [1].

$$
\begin{aligned}
& \langle\varphi\rangle^{f}=\frac{1}{V_{f}} \int_{V_{f}} \varphi d V \\
& \langle\varphi\rangle^{s}=\frac{1}{V_{s}} \int_{V_{s}} \varphi d V
\end{aligned}
$$

For instance, the Darcian velocity which is the macroscopic (or superficial) velocity can be defined by the following equation:

$$
\langle u\rangle=\frac{1}{V} \int_{V} u d V=\frac{1}{V} \int_{V_{f}} u d V
$$

There is a difference between the intrinsic volume averaged value of $\varphi$ and its local (microscopic) values. The deviation of the quantity $\varphi$ from its intrinsic volume averaged value is shown by $\varphi^{\prime}$ and this fluctuation can be defined as [1]

$$
\varphi^{\prime}=\varphi-\langle\varphi\rangle^{f}
$$

The volume average of the multiplication of two quantities can be calculated from the following relation:

$$
\left\langle\varphi_{1} \varphi_{2}\right\rangle=\frac{1}{\varepsilon}\left\langle\varphi_{1}\right\rangle\left\langle\varphi_{2}\right\rangle+\left\langle\varphi_{1}^{\prime} \varphi_{2}^{\prime}\right\rangle
$$

By using the definition of the volume averaging and the definitions in Eq. (7) and (8), the macroscopic energy equations can be found as [1] 


$$
\begin{aligned}
\rho_{f} c_{p f}\left(\varepsilon \frac{\partial\langle T\rangle^{f}}{\partial t}+\langle\vec{u}\rangle \cdot \nabla\langle T\rangle^{f}\right)= & k_{f} \varepsilon \nabla^{2}\langle T\rangle^{f}+\nabla \cdot\left[\frac{1}{V} \int_{S} k_{f} T d S\right] \\
& +\frac{1}{V} \int_{S} k_{f} \nabla T d S-\rho_{f} c_{p f} \nabla \cdot\left\langle T^{\prime} \vec{u}^{\prime}\right\rangle
\end{aligned}
$$

$$
\begin{aligned}
\rho_{s} c_{p s}(1-\varepsilon) \frac{\partial\langle T\rangle^{s}}{\partial t}= & k_{s}(1-\varepsilon) \nabla^{2}\langle T\rangle^{s}-\nabla \cdot\left[\frac{1}{V} \int_{S} k_{s} T d S\right] \\
& +\frac{1}{V} \int_{S} k_{s} \nabla T d S
\end{aligned}
$$

Equation (9) represents the macroscopic form of the energy equation for the fluid phase, while Eq. (10) is for the solid phase. The excess terms in the volume averaged energy equations represent the interfacial heat fluxes as defined in the study of Ochoa-Tapia and Whitaker [5].

Local thermal equilibrium between the solid and the fluid phases can be assumed for the most of the convection problems in the porous media. Quintard and Whitaker [7] developed the constraints that must be satisfied for the validity of the thermal equilibrium assumption; the details of these constraints can be seen from their study. If the thermal equilibrium between two phases is valid, $\langle T\rangle^{f}=\langle T\rangle^{s}=\langle T\rangle$ and the summation of Eqs. (9) and (10) yields Eq. (11) for a continuum domain.

$$
\begin{aligned}
& \left(\rho c_{p}\right)_{e} \frac{\partial\langle T\rangle}{\partial t}+\rho_{f} c_{p f}\langle\vec{u}\rangle \cdot \nabla\langle T\rangle=k_{e} \nabla^{2}\langle T\rangle \\
& -\nabla \cdot\left[\frac{1}{V} \int_{S}\left(k_{f}-k_{s}\right) T d S\right]-\rho_{f} c_{p f} \nabla \cdot\left\langle T^{\prime} \vec{u}^{\prime}\right\rangle
\end{aligned}
$$

Here, $\left(\rho c_{p}\right)_{e}$ and $k_{e}$ are the equivalent thermal capacitance and the equivalent thermal conductivity of the continuum domain. These equivalent properties include porosity as well as the thermal properties of both solid and fluid, and defined as presented below. Although the equivalent thermal conductivity equation (Eq. (13)) is straightforwardly comes from the procedure to obtain single macroscopic energy equation explained above, various models which include other parameters such as the particle contact effects have been proposed in the literature to determine the equivalent thermal conductivity of the porous media [8]. The equivalent thermal conductivity is also called as the stagnant thermal conductivity.

$$
\begin{gathered}
\left(\rho c_{p}\right)_{e}=(1-\varepsilon) \rho_{s} c_{p s}+\varepsilon \rho_{f} c_{p f} \\
k_{e}=(1-\varepsilon) k_{s}+\varepsilon k_{f}
\end{gathered}
$$

The last two terms in the macroscopic energy equation (Eq. (11)) have been distinctively defined as thermal tortuosity and thermal dispersion. These terms do not exist in the microscopic energy equations and they are resulted from the volume averaging procedure. The thermal tortuosity term regards the change of the thermal diffusion path due to different thermal conductivities between the solid and the fluid. It is described as an elongation in the thermal path due to the existence of the solid particles [9]. The thermal tortuosity permits to report on the perturbation of heat flow due to inclusions or cavities dispersed in the medium [10]. Tortuosity vanishes if $\left(k_{f}-k_{s}\right) T$ is constant over the interface and it is usually negligible [1].

The term $\rho_{f} c_{p f}\left\langle T^{\prime} \vec{u}^{\prime}\right\rangle$ is analogous to the turbulent heat flux in the turbulent convection heat transfer, which accounts for the contributions from mechanical dispersion, and can be modeled similarly by a gradient-type diffusion hypothesis [1]. Hence, the thermal dispersion term in Eq. (11) can be written in the form of a heat diffusion transport and defined by using the thermal dispersion conductivity $\left(k_{\mathrm{dis}}\right)$ as follows:

$$
-\rho_{f} c_{p f} \nabla \cdot\left\langle T^{\prime} \vec{u}^{\prime}\right\rangle=k_{\mathrm{dis}} \nabla^{2}\langle T\rangle
$$

As can be seen from Eq. (14), the thermal dispersion depends on the thermophysical properties of the fluid phase and the temperature and the velocity fluctuations in the porous medium due to the existence of two different phases. Thus, the thermal dispersion conductivity term contains both the effects of the nonuniformities in the temperature and velocity. By substituting Eq. (14) into Eq. (11) and neglecting the thermal tortuosity term, the macroscopic energy equation for a continuum domain involving both the solid and the fluid phases takes the new form presented by Eq. (15).

$$
\left(\rho c_{p}\right)_{e} \frac{\partial\langle T\rangle}{\partial t}+\rho_{f} c_{p f}\langle\vec{u}\rangle \cdot \nabla\langle T\rangle=k_{\mathrm{eff}} \nabla^{2}\langle T\rangle
$$

where $k_{\text {eff }}$ is the effective thermal conductivity which is the summation of the equivalent thermal conductivity of the continuum domain and the thermal dispersion conductivity.

$$
k_{\mathrm{eff}}=k_{e}+k_{\mathrm{dis}}
$$

The effective thermal conductivity is defined by Eq. (13) and the thermal dispersion conductivity can be found experimentally or numerically. The general procedure of the numerical calculation is given in the next section. Thermal dispersion occurs in the different directions in a porous medium due to the nonuniform velocity effects and the temperature gradient. The value of the effective thermal conductivity depends on various parameters such as fluid velocity, porosity, the shape of pores, and the solid and the fluid thermal properties [2]. Since the heat diffusion occurs in all directions, the effective thermal conductivity is a tensor whose diagonal terms represent the longitudinal and the transverse effective thermal conductivities of the continuum domain.

Most of the researchers prefer to determine effective thermal conductivity ratio, which is the ratio of the effective thermal conductivity to the fluid thermal conductivity. The most of the proposed relations are in terms of the particle-based Reynolds number or Peclet number $\left(k_{\mathrm{eff}} / k_{f}=f(\operatorname{Re}, \mathrm{Pr})\right)$. For a porous medium, the particle-based Reynolds number is defined as $\operatorname{Re}=\rho_{f}\langle u\rangle d_{p} / \mu_{f}$ where $\langle u\rangle$ is the macroscopic velocity, $d_{p}$ is the equivalent particle diameter, and $\mu_{f}$ is dynamic viscosity of the fluid. The particle-based Peclet number is the multiplication of the particle-based Reynolds number with Prandtl number of the fluid.

\section{Determination of the Thermal Dispersion}

When the macroscopic approach is employed to analyze heat and fluid transport in a porous medium, the effective thermal conductivity including both stagnant and thermal dispersion conductivities should be known, precisely. Several numerical and experimental studies on the determination of the effective thermal conductivities in the longitudinal and the transverse directions are reported in the literature. The experimental studies have been performed for the packed beds. Fluid flows through the packed bed, between the solid particles by using power of an external fan or a pump. The bed is heated (or cooled) from the boundaries or from the inside; thus the temperature of the bed is increased (or decreased) and heat transfer occurs between the bed and fluid flowing through the bed. By measuring the fluid temperature at different locations in the bed and comparing the solution of the macroscopic energy equation with the experimental data, the effective thermal conductivity can be determined. In the numerical studies, Navier-Stokes and energy equations are solved for a control volume inside a porous medium, and the microscopic velocity and temperature distributions are obtained, numerically. Then, the volume integrations of these fields are used to determine the macroscopic transport properties like the effective thermal conductivity and the permeability. For the theoretical calculation 
of $k_{\text {eff }}$ the following equation can be used, which straightforwardly comes from Eq. 14 [11]:

$$
k_{\mathrm{eff}}=k_{e}+\frac{\rho_{f} c_{p f}}{V_{f} \nabla\langle T\rangle} \int_{V f}(u-\langle u\rangle)(T-\langle T\rangle) d V
$$

where $k_{e}$ is given by Eq. (13).

Kuwahara and Nakayama [11] obtained the transverse and the longitudinal thermal dispersion conductivities for a lattice of square rods with numerical calculation. Kuwahara et al. [12] studied regularly spaced square rods in an infinite space, numerically. The transverse coefficients of the thermal dispersion and the molecular diffusion due to tortuosity were found. $\mathrm{Xu}$ et al. [13] examined an array of parallel plates to determine the thermal dispersion in fully-developed laminar flow with steady and transient conditions. A correlation for the effective thermal diffusivity $\left(k_{\mathrm{eff}} / \rho c_{p}\right)$ in the longitudinal direction was numerically found. Pedras and de Lemos [14] studied a periodic array of the longitudinally placed elliptic rods in an infinite porous medium and calculated the thermal dispersion tensor, numerically. The correlations for both $x$ and $y$ components of the dimensionless thermal dispersion tensor $\left(k_{\mathrm{dis}} / k_{f}\right)$ were proposed.

Quintard et al. [15] studied two- and three-dimensional spherical or square cylinders, numerically. Thermal dispersion coefficients were found with using thermal equilibrium and nonequilibrium conditions. The comparison between the theoretical and experimental results was done. Hsu and Cheng [16,17] also proposed a theoretical model for the thermal dispersion conductivity based on the volume averaging method. Other numerical studies on the determination of the thermal dispersion can be found in the literature [18-21]. The proposed correlations for the determination of the thermal dispersion usually include Peclet number.

A review of some experimental studies on the determination of the thermal dispersion conductivity of porous media was given by Kaviany [2]. Additionally, Quintard and Whitaker [22] reviewed transport in porous media. The comparisons of some of the experimental studies for the determination of the thermal dispersion were presented in their studies. However, in the present study, the classifications reported in the literature are expanded and the experimental methods are classified based on the heating conditions of the test sections of the experimental setups. Moreover, the studies performed in the recent years for the determination of the effective thermal conductivity in the packed beds are explained and details of the experimental studies are provided. The comparisons between the experimental apparatus, procedures and results are discussed via tables and diagrams.

\section{Experimental Studies on the Thermal Dispersion}

The experimental studies on the determination of the effective thermal conductivity are presented in detail. Different porous shapes have been used in the performed studies. Many researchers preferred to use the spherical particles while some others used the cylinders, Raschig rings, etc. The employed porous materials show variety as well. Most of the researchers have used spherical glass particles, while ceramic and steel materials have also been used. As the fluid, air is used mostly while water also has been used in some of the investigations. Some investigators preferred to determine the effective thermal conductivity under steady state circumstances while the others used transient state. Generally, thermal equilibrium condition was assumed for the determination of the effective thermal conductivity.

Basically all the experimental methods follow the same procedure. Experiments on the determination of the effective thermal conductivity are generally performed by measuring the temperatures at various locations inside a packed bed when a heat input is imposed. The heat source used to generate the temperature gradient in the bed has been applied inside the packed bed or imposed at the bed boundaries. To determine the effective thermal conductivity which includes both the equivalent thermal conductivity of the porous medium and the thermal dispersion conductivity, the following procedure is followed:

- A temperature gradient in the packed bed is generated by using a heat source/sink.

- Temperatures at the different packed bed locations are measured.

- The macroscopic energy equation (i.e., Eq. (15)) is solved for the packed bed. In most of the studies, analytical methods were used to obtain the solution of Eq. (15).

- Finally, the effective thermal conductivity for the considered packed bed is found by the comparison of the temperature fields obtained from the analytical solution and the measurements.

Analysis of the related literature shows that the experimental studies can be classified into three groups (Fig. 2):

(1) heat addition/removal at the lateral boundaries,

(2) heat addition at the inlet/outlet boundary,

(3) heat addition inside the bed.

In the following sections, these approaches are explained and the reported experimental studies are also presented for each method, separately. Based on the thermal boundary condition and heat source type, each method is also classified into subgroups. These subgroups are explained in the following sections in detail as well.

4.1 Heat Addition/Removal at the Lateral Boundaries. In this approach, the temperature gradient in the bed is provided by imposing uniform temperature or heat flux at the lateral boundaries of the packed bed. The imposed temperature at the bed boundary should be different than the fluid inlet temperature to create the temperature gradient in the bed. The cylindrical packed beds have been mostly used to provide an axisymmetrical condition. The use of the axisymmetrical packed bed provides advantages such as checking of the measured temperature at different locations and the simplification of the macroscopic energy equation. Steady state heat addition/removal at the lateral boundaries has been performed in the most of the studies. In all studies that are discussed in this section, thermal equilibrium condition is assumed for the determination of the effective thermal conductivity. Hence, the comparison of the solution of the steady state macroscopic energy equation

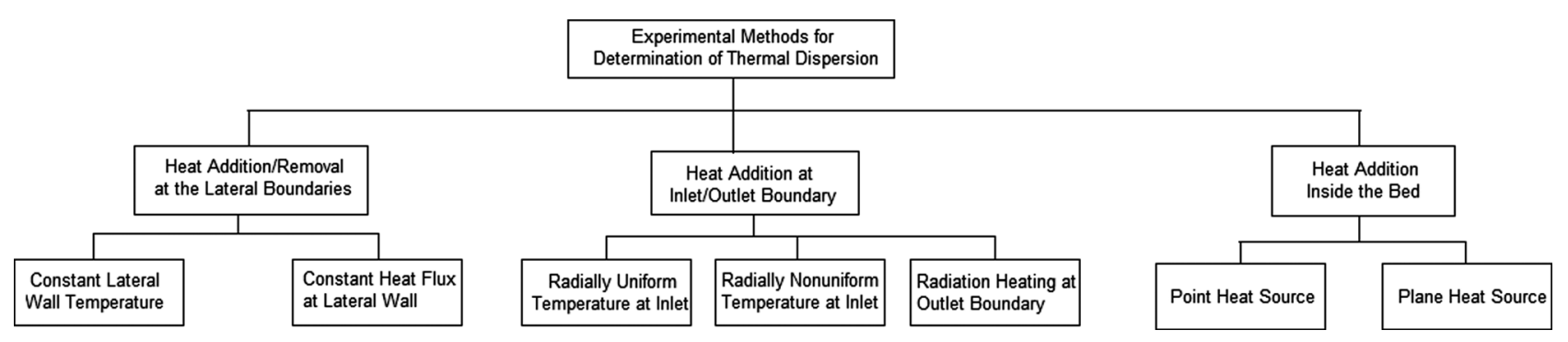

Fig. 2 The experimental methods for the determination of the thermal dispersion 
with the experimentally achieved temperature profiles at steady state yields the effective thermal conductivity value. The macroscopic energy equation presented by Eq. (18) was used to determine the temperature distribution in the bed for the most experimental studies in which the cylindrical bed was used.

$$
\left(\rho c_{p}\right)_{f}\langle u\rangle \frac{\partial\langle T\rangle}{\partial z}=k_{e r}\left[\frac{\partial^{2}\langle T\rangle}{\partial r^{2}}+\frac{1}{r} \frac{\partial\langle T\rangle}{\partial r}\right]+k_{\mathrm{eax}} \frac{\partial^{2}\langle T\rangle}{\partial z^{2}}
$$

where $k_{e r}$ and $k_{\text {eax }}$ are the radial (transverse) and the axial (longitudinal) effective thermal conductivities, respectively. The axial diffusion was neglected in some studies [23-27]; however, both radial and axial effective thermal conductivities were calculated in the study of Bunnell et al. [28]. Some researchers preferred to include axial heat diffusion while the value of the axial effective thermal conductivity was calculated based on the previously reported correlations $[29,30]$. The imposed boundary conditions for Eq. (18) are

- convective heat transfer or constant heat flux at the lateral surface

- uniform temperature at the inlet

- constant temperature that equals to the lateral wall temperature at the outlet (if it is required)

- symmetry at the center of the packed bed

In Fig. 3, the schematic view of an experimental setup that summarizes the main components of the apparatus used in the experimental studies is shown. As seen from Fig. 3, the fluid with a specified mass flow rate firstly enters to the preheating section to increase the fluid temperature to a specified value. The preheating section is also filled with the studied porous medium. Then, it passes through the calming section providing fully developed velocity field. After the calming section, it enters to the main section whose lateral surface temperature is different than the fluid inlet temperature. In this section (test section), the temperatures at different points of the bed (longitudinal or transverse) is measured. Based on the obtained local temperature, longitudinal or transverse temperature profiles can be obtained. In some studies, the preheating or the calming sections were not involved in the setup.

The available reported studies, which used heat addition/removal at the lateral boundaries method, are briefly explained below.

Smirnov et al. [23] studied heat transfer in the cylindrical packed beds filled with steel and glass spheres, ceramic cylinders, and ceramic and copper Raschig rings. The performed study was done for the range of Reynolds numbers from 250 to 2250. The heat diffusion in the axial direction was neglected. The heat removal at the lateral boundary was done by circulating water in an annular jacket. In the study, the effective thermal conductivity and the related wall heat transfer coefficient were found. A model with a linear variation of the radial effective thermal conductivity in the vicinity of the wall was proposed for the description of the radial heat transfer in the packed bed. It was indicated that the radial effective thermal conductivity can be predicted by the following relation:

$$
\frac{k_{e r}}{k_{f}}=\frac{k_{e}}{k_{f}}+K \operatorname{Re} \operatorname{Pr}
$$

where $K$ is the convective heat transport parameter and depends on the porous structure. Some experimental values for $K$ and the wall heat transfer coefficient were obtained as given in Table 6.

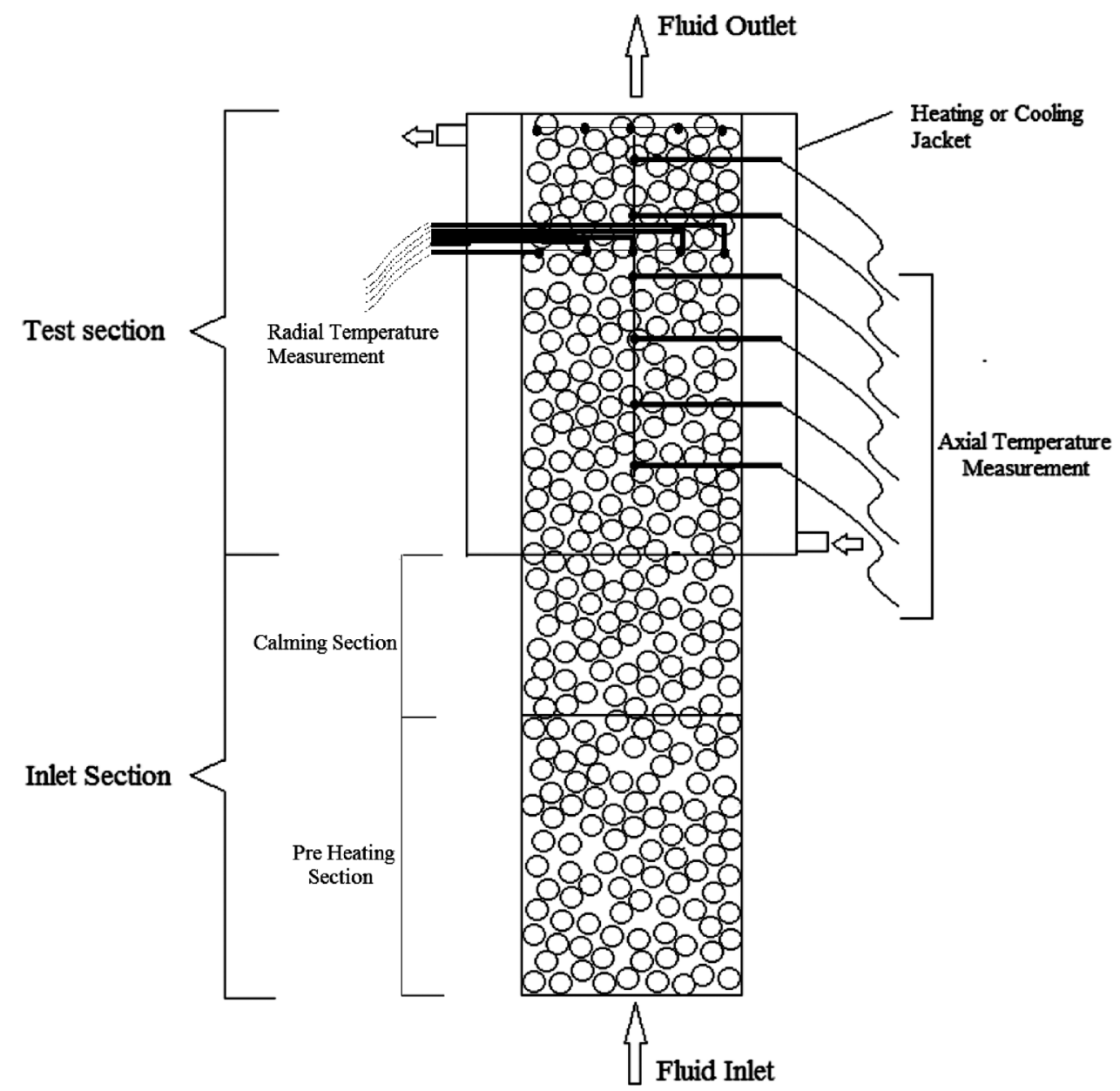

Fig. 3 The schematic view of the experimental setup for the use of the heat addition/removal at the lateral boundaries method 
Smirnov et al. [24] also studied 4-hole and 52-hole cylindrical pellets, 6-spoke wheels and 3-hole trilobed particles as packing with the same experimental setup that was used in the previous study [23]. All particles were made of ceramic. The Reynolds number range of 400-2300 was examined. It was claimed that the shape of the particles used in the packed bed can significantly improve the radial heat transfer and reduce the pressure drop. It was remarked that the proposed model (Eq. (19), Ref. [23]) can describe the radial thermal conductivity for all type of particles used in the study without requiring any additional empirical parameters except the value of the convective heat transport parameter $K$.

Smirnov et al. [25] also performed another study and investigated the heat transfer in a cylindrical packed bed filled with copper and ceramic particles with various shapes (cylinder, Raschig ring, six-spoke wheels, etc.). In the performed experiments, Re number was greater than 300 . The values of the convective heat transport parameter given in Eq. (19) for different shapes of copper and ceramic particles were found. The obtained $K$ values for different packings are shown in Table 6 .

Thomeo and Freire [26] studied the heat transfer in a cylindrical packed bed filled with glass spheres. Air flow with Reynolds numbers between 60 and 190 was studied. The air temperature was reduced at the main test section having heat removal at the lateral boundary by imposing constant wall temperature. The axial diffusion was neglected. A correlation was not proposed for the determination of the radial effective thermal conductivity.

Demirel et al. [27] studied air flow in a rectangular duct filled with polyvinyl chloride Raschig rings for Reynolds numbers with the range of 200-1200, and polystyrene spheres for Reynolds numbers with the range of 200-1450. The bed was placed horizontally and a uniform heat flux with the range of $50-170 \mathrm{~W} / \mathrm{m}^{2}$ was applied at the top wall while the other surfaces were insulated. Instead of the theoretical solution for the determination of the temperature distribution, a third order polynomial function was assumed to predict the temperature distribution in the bed. The coefficients of the polynomial function were obtained by using the experimental data. The suggested correlations for the determination of the transverse effective thermal conductivity of two packings as Raschig rings and spheres are given in Table 6.

Bunnell et al. [28] investigated the heat transfer in a cylindrical packed bed with alumina cylinders. Reynolds numbers with the range between 30 and 100 were studied. The lateral surface of the bed was held at a constant temperature $\left(100{ }^{\circ} \mathrm{C}\right)$ that was lower than the inlet air temperature $\left(400^{\circ} \mathrm{C}\right)$ by using boiling water circulation in the jacket of the bed. Thermocouples were placed in such a way that both fluid and solid temperatures were measured in the radial direction. The effective thermal conductivities for the radial and the axial directions were assumed equal and the solution Eq. (18) was obtained under this assumption. The obtained correlation for the determination of the effective thermal conductivities is displayed in Table 6 .

Wen and Ding [29] studied a cylindrical packed bed of glass spheres with air as the fluid. Re numbers with the range between 100 and 700 were considered. The whole lateral surface of the packed bed was heated and maintained at constant wall temperature. The thermocouples were distributed both in the axial and the radial directions. The temperature difference between solid and fluid phases was checked. The study was performed for both transient and steady-state conditions. In the transient conditions, only the temperature distribution variations with time inside the bed were investigated. The radial effective thermal conductivity and the wall heat transfer coefficient were determined by the comparison of the steady-state experimental results with the analytical solution of Eq. (18). The axial effective thermal conductivity was directly calculated from Eq. (20) which was proposed by Wakao et al. [31]:

$$
\frac{k_{\mathrm{eax}}}{k_{f}}=\frac{k_{e}}{k_{f}}+0.5 \operatorname{Re} \operatorname{Pr}
$$

It was declared that the correlations of the radial effective thermal conductivity of Bunnell et al. [28] and Demirel et al. [27] provide well predictions.

Dixon and van Dongeren [30] studied a cylindrical packed bed with spherical particles of porous ceramic, nylon and steel. The effects of the tube (packed bed) and the particle diameters on the heat transfer were investigated for the fixed tube-to-particle diameter ratios of 4 and 8 . The Re number interval was between 100 and 900 . Steam was circulated in the jacket of the tested section to provide constant wall temperature. Both the axial and the radial temperature measurements were achieved. Equation (18) and its boundary conditions were used to find an analytical expression for the temperature distribution through the bed. For the axial effective thermal conductivity, the following equation was used:

$$
\frac{k_{\text {eax }}}{k_{f}}=0.5 \operatorname{Re} \operatorname{Pr}+\frac{k_{s}}{k_{f}}
$$

where $k_{s} / k_{f}$ was taken as 18,8 , and 4 for steel, porous ceramic, and nylon packings, respectively. The radial effective thermal conductivity and the wall Nusselt number values were found for various Re numbers. It was found that the radial effective thermal conductivity can be described based on the value of tube-to-particle diameter ratio rather than the individual tube and particle diameters.

Borkink and Westerterp [32] studied a cylindrical packed bed with glass spheres of two different diameters as $3.7 \mathrm{~mm}$ for the Peclet number range of $60-300$ and $7.2 \mathrm{~mm}$ for the Peclet number range of 100-800. Moreover, porous alumina cylinders for $50<\mathrm{Pe}<450$ and porous alumina Raschig rings for $100<\mathrm{Pe}<450$ were studied. The study was performed for three stainless steel beds with different inner diameters. Air was used as fluid phase. The experimental setup was constructed to measure both the radial and the axial temperature values throughout the packed bed. Hot air entered to the bed while cooling of the fluid was made by the lateral walls with constant temperature. No calming section was involved in the setup. For the steady state, the radial temperature profile was measured near the top section of the bed. Dimensionless form of Eq. (18) was solved and the axial conduction was neglected. A correlation that relates the radial effective thermal conductivity with the Peclet number, the particle shape, and the number of particles on the tube (packed bed) diameter was obtained. The obtained correlation is illustrated at Table 6 .

The same packed bed setup [32] was studied for Pe numbers between 150 and 2100 by the same researchers [33]. Similar to the previous study, the dimensionless form of Eq. (18) without the axial dispersion was solved. Based on the obtained results, it was declared that the inlet boundary condition in the modeling of the radial effective thermal conductivity is very important. If the inlet temperature profile is assumed to be radially flat, although the actual profile is curved, an axial dispersion may occur. The radial effective thermal conductivity and the wall heat transfer coefficient were found to be strongly cross-correlated and both parameters were found to be independent of the tube diameter.

Furthermore, the same experimental setup with alumina cylinder packings was used [34]. Reynolds numbers between 70 and 600 were considered. The dimensionless form of Eq. (17) with axial conduction was solved, numerically. The influences of the inlet and the outlet boundary conditions on the solution were investigated. The values of the axial effective thermal conductivity, the radial effective thermal conductivity and the wall heat transfer coefficient were found for various Reynolds numbers and bed diameters. These results were obtained with the assumption of a parabolic temperature profile at the inlet. It was declared that the inclusion of the axial thermal dispersion in the heat balance does not significantly influence the description of the heat transport in wall cooled or heated packed bed if the correct radial inlet temperature profile is selected and the employed Reynolds numbers exceed 50.

Kwong and Smith [35] studied two different sizes of the cylindrical packed beds with air and ammonia. The packing materials 


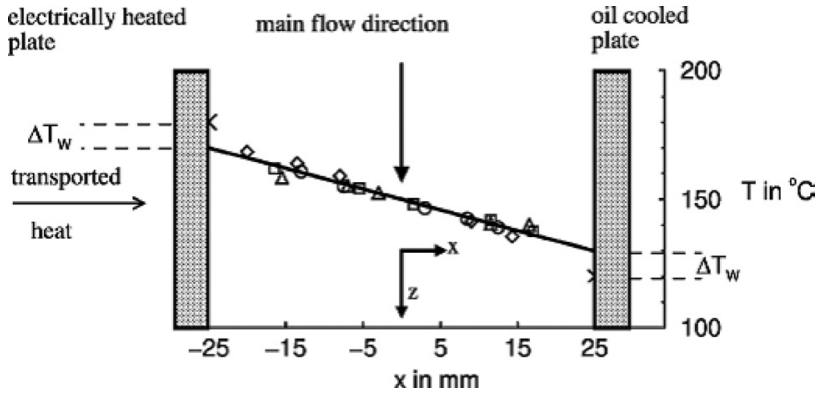

Fig. 4 Experimental setup of Bey and Eigenberger [36], this figure was published in Ref. [36]. Copyright 2001 Elsevier Masson sAS. All rights reserved.

were steel and alumina spheres. The nonheated calming section was not involved in the study, but the inlet temperature measurements were taken at about $18 \mathrm{~cm}$ above the actual inlet of the bed to reduce entrance disturbances. To find theoretical temperature distribution, Eq. (18) was solved, numerically. The term for the axial heat transfer by diffusion was neglected. The radial effective thermal conductivity values were found for Reynolds numbers between 50 and 450 .

Bey and Eigenberger [36] studied the packed bed (tube) with glass and ceramic spheres, and ceramic ring packings with tubeto-particle diameter ratios between 3.3 and 11. The studied Reynolds number range was between 50 and 900 for the spheres and between 0 and 2500 for the rings. The experiments were conducted with the packing materials between two parallel plates of different temperatures (Fig. 4). By this way, instead of solving Eq. (18) with the aforementioned boundary conditions (in the case of the cylindrical beds), the radial effective thermal conductivity and the wall heat transfer coefficient were described by using Eq. (22) and (23) where $q_{w}^{\prime \prime}$ is the wall heat flux and $h_{w}$ is the wall heat transfer coefficient. The results of Eq. (22) and (23) were compared with the experimental data.

$$
\begin{gathered}
q_{w}^{\prime \prime}=k_{e r} \frac{d T}{d x} \\
q_{w}^{\prime \prime}=h_{w}\left[T_{w}-T(r=R)\right]
\end{gathered}
$$

It was claimed that the value of the radial effective thermal conductivity can be well described by the correlation developed by Bauer and Schlünder [37] (Eq. (24)), where $K_{r}$ is a correlation constant. $K_{r}$ values for different tube-to-particle diameters were shown in diagrams in their study.

$$
\frac{k_{e r}}{k_{f}}=\frac{k_{e}}{k_{f}}+\frac{\mathrm{Pe}}{K_{r}}
$$

Jorge et al. [38] studied a cylindrical packed bed filled with cylindrical particles. Air was used as fluid. The packing material was an industrial catalyst made of nickel supported on alumina. Reynolds numbers between 87 and 290 was studied. The radial effective thermal conductivity and the wall heat transfer coefficient were estimated from the steady state data while the characteristic bed time constant was estimated from the transient data from the experiments. The test section was heated by using a steam jacket and the uniform temperature at the lateral surface was checked. A new correlation was proposed for the radial effective thermal conductivity. Equation (18) was numerically solved to obtain the temperature distribution. A correlation developed by Dixon and Cresswell [39] (Eq. (25)) was used for the determination of the axial effective thermal conductivity, where $G$ is the superficial mass flow rate.

$$
k_{\text {eax }}=G c_{p f} d_{p}\left[\frac{0.5}{1+9.7 \varepsilon / \mathrm{Pe}}+\frac{0.73 \varepsilon+k_{s} / k_{f}}{\mathrm{Pe}}\right]
$$

Dekhtyar et al. [40] studied a cylindrical packed bed of glass spheres. The fluids were water and $47 \%$ aqueous solution of glycerin. Reynolds number range of 3-700 was examined. Constant heat flux at the surface boundary was used in the experimental setup. Equation (18) was solved without considering the axial component of diffusion heat transfer to obtain an analytical expression for the temperature profile. In the obtained analytical solution, temperature depends on $r^{2}$ and $x$. Equation (26) was presented based on the obtained analytical expression. A parabolic temperature profile was assumed in the packed bed and then Eq. (26) was found by using the parabolic temperature profile.

$$
k_{e r}=\frac{q_{w}^{\prime \prime}}{D \partial T / \partial\left(r^{2}\right)}
$$

The radial effective thermal conductivity was calculated from Eq. (26) with using the temperature data from the experiment $(D$ is the tube diameter). A correlation was obtained for the radial effective thermal conductivity ratio. It was claimed that the proposed correlation was adequate for the turbulent range whereas some stratification of data was observed for the low Reynolds number regions. It was also mentioned that the effective thermal conductivity ratio is proportional to the square root of the Peclet number for the Reynolds numbers below 100 .

Gunn and Khalid [41] studied air flowing cylindrical packed beds with glass and metallic particles. The investigated Reynolds number range was between 1 and 400. The packed bed had an unheated inlet section and then the lateral walls were heated by steam. Eq. (18) was used to obtain the analytical solution. The axial and the radial thermal dispersion conductivities were achieved. The results were shown by the graphics of the axial and the radial Peclet numbers constructed with the dispersion conductivities versus Reynolds number.

4.2 Heat Addition at the Inlet/Outlet Boundary. Heat addition at the inlet/outlet boundary approach used most frequently in the early studies of the heat transfer in porous media. A review of those studies can be found in Kaviany [2]. In some studies, mass transfer experiments were conducted based on this method and the effective thermal conductivity values were obtained by analogy between the heat and mass transfer [42]. Generally, thermal equilibrium condition was assumed for the determination of the effective thermal conductivity. In this method, the bed can be heated at the inlet or outlet boundaries to provide a temperature gradient. A sample experimental setup for the heat addition at the inlet/outlet boundary is provided and shown in Fig. 5, schematically. Similar to the heat removal/addition at the lateral boundaries (Fig. 3), the experimental setup consists of a calming section and a test section. There is an electrical heater array at the inlet of test section and the temperature of the bed increases at the inlet boundary of the bed. In some cases, the heat step input is provided by pumping the fluids from two reservoirs at the different temperatures. The lateral boundary of the bed is insulated. Then, temperature distributions in longitudinal and transverse directions in the bed is measured and plotted. Our literature review shows that two methods can be applied for the heat addition at the inlet boundary. The methods used for the heat addition at the inlet/outlet boundaries are explained below. The first and the second methods are used for the heating at the inlet boundary while the third method is used for the heating at the outlet boundary.

(a) In the first method used for the heating at the inlet boundary, temperature gradient can be generated by a heat source and applied at the bed inlet plane. The effect of the temperature gradient at the bed inlet plane is propagated through the bed and then it is measured. A temperature gradient in the radial direction of the bed can be obtained by partial heating of the inlet section of the packed bed. Generally, a steady condition is 


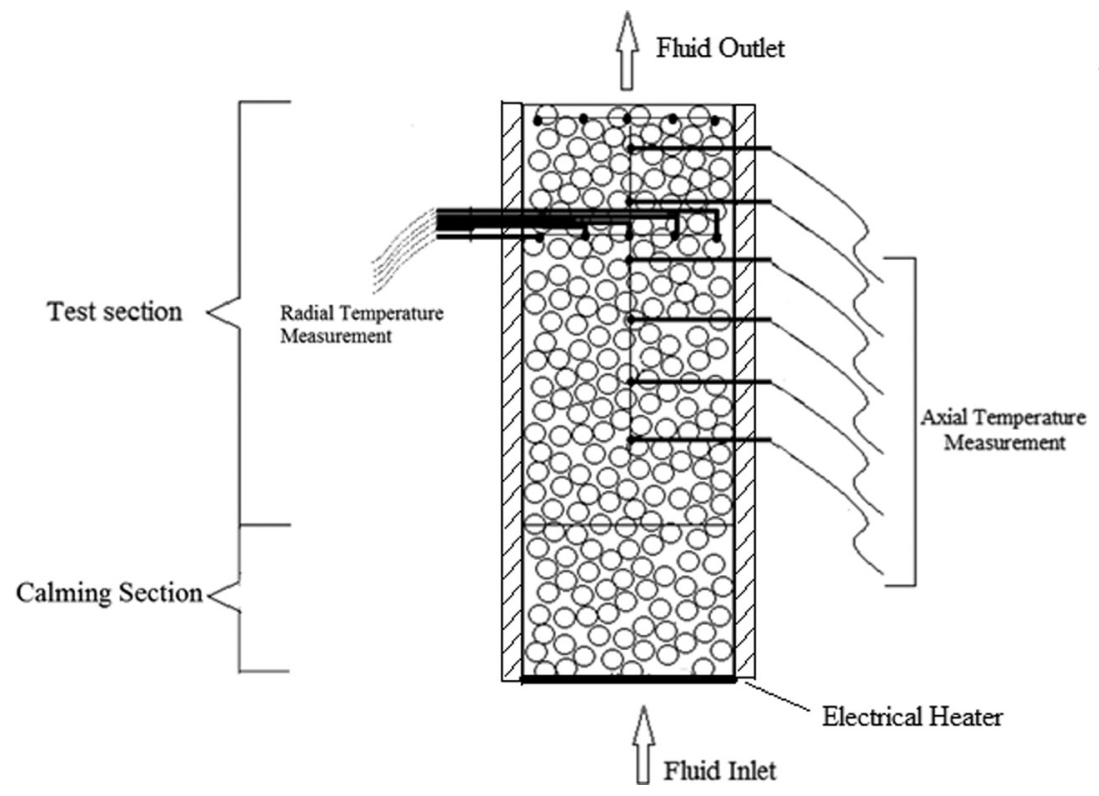

Fig. 5 The schematics of the experimental setup for the heating at the inlet boundary

conducted to determine the thermal dispersion. The transverse and longitudinal components of the effective thermal conductivity can be found by comparing theoretical solution of Eq. (27) with temperature measurements.

$$
\left(\rho c_{p}\right)_{f}\langle u\rangle \frac{\partial\langle T\rangle}{\partial z}=k_{\mathrm{etr}} \frac{\partial^{2}\langle T\rangle}{\partial x^{2}}+k_{\mathrm{eax}} \frac{\partial^{2}\langle T\rangle}{\partial z^{2}}
$$

where $k_{\text {etr }}$ and $k_{\text {eax }}$ are the transverse and the longitudinal (axial) effective thermal conductivities, respectively. The imposed boundary conditions are:

- radially uniform or nonuniform temperature at the inlet,

- zero heat flux at the lateral boundaries,

- symmetry at the center of the packed bed,

- no diffusion heat flux at the outlet.

(b) In the second method used for the heating at the inlet boundary, transient experiments were conducted by using radially uniform temperature at the inlet of the packed bed. A step change, a pulse heat input, or a sinusoidal temperature variation in time can be imposed at the bed inlet and consequently the outlet air temperature varies with time. For a step change, a sudden temperature change is applied at the bed inlet boundary and then the inlet temperature remains constant. For a pulse heat input, a finite amplitude pulse is applied by the heater and it is repeated periodically. With a similar arrangement, a sinusoidal change in temperature can also be achieved. The measurements are made for temperature in the downstream temperature and/or time lag difference between the waves at the inlet and outlet of the packed bed. The walls of the bed are insulated and consequently the axial conductive and convective heat transports become dominant. Because of these assumptions, the one-dimensional transient form of the macroscopic energy equation (Eq. (28)) can be used to obtain the theoretical solution of the temperature in the bed.

$$
\left(\rho c_{p}\right)_{e} \frac{\partial\langle T\rangle}{\partial t}+\left(\rho c_{p}\right)_{f}\langle u\rangle \frac{\partial\langle T\rangle}{\partial z}=k_{\mathrm{eax}} \frac{\partial^{2}\langle T\rangle}{\partial z^{2}}
$$

The following initial and boundary conditions can be implemented for the boundaries:
- for the inlet boundary condition, a time dependent temperature can be used (e.g., sinusoidal wave with constant amplitude),

- a uniform temperature for the initial condition,

- the measured outlet temperatures can be used.

(c) The third method is used for heating at the outlet boundary. Heating at the outlet of the packed bed can be done by using an infrared lamp. Thus, the radiation heating from the external of the bed is used to create the temperature gradient inside the bed. Equation (27) is considered to obtain the theoretical temperature distribution. Figure 6 displays the schematic view of the experimental setups used in the studies in which the radiation heating method was applied. Equation (27) is used without heat diffusion in the transverse direction to obtain the analytical temperature distribution in the packed bed.

Gunn and De Souza [43] studied the thermal frequency response of the packed beds by using a similar method as described above. The packing materials were glass, steel and lead spheres. Air was used as fluid and the Reynolds number range between 0.05 and 330 was studied. A grid heater was placed at the inlet of the packed bed and sinusoidal heating was applied via this heater. Low thermal conductivity materials were used at the walls of the packed bed; hence the radial heat transfer was kept small compared to the axial heat transfer. The axial dispersion coefficient and the fluid-particle heat transfer coefficient were found by a nonlinear regression. The experimental frequency response was observed to be mostly influenced from the thermal dispersion at Reynolds numbers less than 1.

Clement and Jorgensen [44] studied the axial and the radial dispersion coefficients under nonreacting and reacting conditions. A cylindrical packed bed with Pt-impregnated alumina pellets as packing was used. The lateral walls were insulated. At the beginning of the experiments, the packed bed was allowed to reach the steady state. After some time, a periodical temperature pulse was applied at the bed inlet. Then the transient measurements were done. Three steady state temperature profiles were examined with different inlet conditions. All experiments were conducted for Reynolds number of 10 . Thus the values of dispersion coefficients for this Reynolds number were found. The dimensionless, 2D, and cylindrical form of Eq. (28) was solved analytically to obtain the 


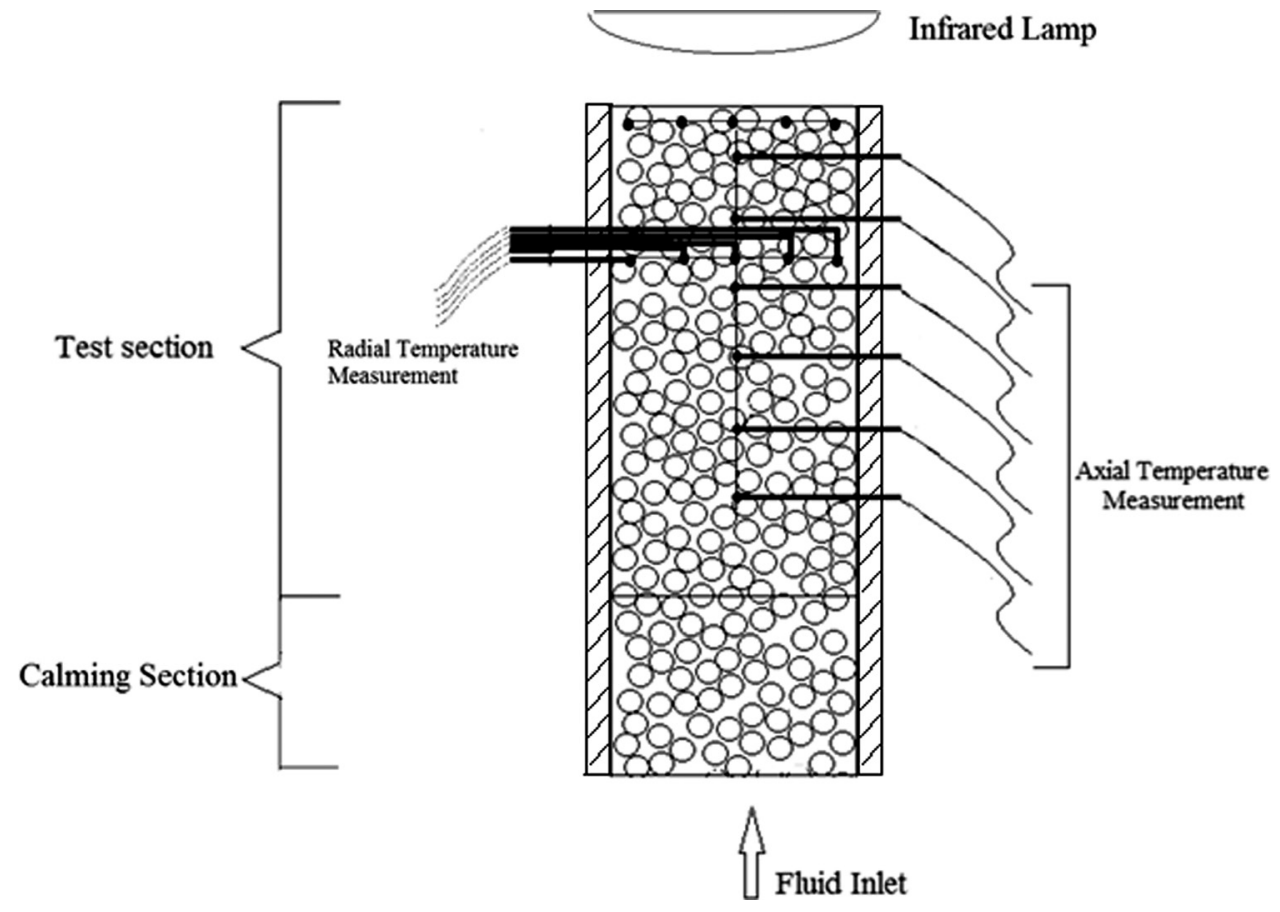

Fig. 6 The schematic of experimental setups in which the radiation heating method was used

temperature distribution in the bed. It was concluded that for nonreacting conditions, in order to obtain accurate values of the axial thermal dispersion coefficients, it is necessary to include the radial thermal dispersion in spite of the insulation at lateral walls.

Levec and Carbonell [45] investigated the thermal response of a rectangular packed bed due to step temperature changes. Water was used as fluid. Peclet number range from 10 to 1000 was studied. The packing was urea formaldehyde spheres. A flow distributor was used at the setup to provide uniform velocity. Transient experiments were conducted by employing a step temperature change in water. Fluid and solid temperatures were measured separately at six axial locations as a function of time. Transverse diffusion was neglected and the axial effective thermal conductivity values were obtained. Thermal nonequilibrium was considered and the macroscopic energy equations for the solid and the fluid phases were solved, separately. It is mentioned that there are three factors affecting the axial effective thermal conductivity: firstly conduction, secondly hydrodynamic dispersion, and finally the heat exchange between solid and fluid. In their study, some steady experiments were conducted to measure the transverse effective thermal conductivity. For these measurements nonuniform temperature at the inlet was used by contributing different temperatures at the two halves of the packed bed. Eq. (27) was used to obtain the transverse effective thermal conductivity values with neglecting axial diffusion.

Elsari and Hughes [46] investigated the axial effective conductivity for a cylindrical packed bed with different packing materials. Air, nitrogen and carbon dioxide were used as fluid in the study. Packing materials were steel ball bearings, copper chromite and chromia alumina cylinders, alumina hollow cylinders, and alumina spheres. Two types of the packed beds were used as a glass bed and a thin walled steel bed. The lateral surfaces of the beds were insulated. Heat input was given at the outlets of the beds by using an infra-red lamp of $375 \mathrm{~W}$. Equation (27) was first considered with using uniform temperatures at the inlet and outlet and with neglecting radial conduction. Additionally, in order to calculate the radial heat losses, Eq. (29) was used. It was observed that the axial effective thermal conductivity strongly depends on particle size.

$$
\left(\rho c_{p}\right)_{f} u \frac{\partial\langle T\rangle}{\partial z}+k_{\mathrm{eax}} \frac{\partial^{2}\langle T\rangle}{\partial z^{2}}+\frac{4 h_{w}}{D}\left(\langle T\rangle-T_{i}\right)=0
$$

where $h_{w}$ is the wall heat transfer coefficient, $D$ is the tube diameter, and $T_{i}$ is the inlet gas temperature.

Yagi et al. [47] studied a cylindrical packed bed with insulated walls for low Reynolds numbers. Glass and metal spherical particles were used as packing materials. The packed bed was heated from the top by an infrared lamp. The axial effective thermal conductivity values were obtained by using Eq. (27). The radial diffusion was neglected. A correlation that related the axial effective thermal conductivity with the Peclet number and the dimensionless stagnant thermal conductivity was found.

Vortuba et al. [48] studied an experimental setup similar to that used by Yagi et al. [46] in order to determine the axial effective thermal conductivity. Reynolds number range from 0.1 to 1000 was studied for air, oxygen, and nitrogen. The packing particles were glass, iron, lead, alumina, sand, and duracryl spheres, ceramic Raschig rings, alumina cylinders, and irregular particles. A $250 \mathrm{~W}$ infrared lamp was used to heat the packed bed from the top. The temperature measurements were done at the packed bed axis. Radial measurements were also done, but no measurable radial temperature gradient was found. To obtain analytical temperature profiles, Eq. (27) was used with neglecting radial heat diffusion. A correlation for the axial effective thermal conductivity was obtained.

Vortmeyer and Adam [49] studied heat transfer in cylindrical packed beds filled with spherical particles. The experiments were conducted with spherical particles of low thermal conductivity, such as catalyst support material $\mathrm{Al}_{2} \mathrm{O}_{3}$ or plastic, with glass spheres of moderate thermal conductivity and metal (steel, bronze, brass) spheres of high thermal conductivity. Air was used as fluid phase. Radial heat losses were included to the analytical solution by using Eq. (29). A correlation for the axial effective thermal conductivity was derived. Additionally, the experimental results of Kunii and Smith [50] were analyzed to include the effects of different gases and another relation was obtained for the axial effective thermal conductivity of packed beds with glass spherical packings.

4.3 Heat Addition Inside the Bed. In this approach, a plane or a point heat source is placed inside the packed bed. Time dependent or steady heat sources can be used. Usually rectangular 
packed beds were used. A wire that is placed perpendicular to the fluid flow can be thought as a point source or several wires in the same plane can be considered as a plane heat source inside the packed bed. Furthermore, a heated spherical particle can be used as a heat addition source in the bed. Both the axial and the transverse components of the effective thermal conductivity can be determined if the thermocouples distributed throughout the packed bed.

The governing equation, which should be solved to determine the axial and the transverse effective thermal conductivities, is given by Eq. (30).

$$
\left(\rho c_{p}\right)_{e} \frac{\partial\langle T\rangle}{\partial t}+\left(\rho c_{p}\right)_{f}\langle\vec{u}\rangle \frac{\partial\langle T\rangle}{\partial x}=k_{\operatorname{eax}} \frac{\partial^{2}\langle T\rangle}{\partial x^{2}}+k_{\mathrm{etr}} \frac{\partial^{2}\langle T\rangle}{\partial y^{2}}+s
$$

where $k_{\text {eax }}$ and $k_{\text {etr }}$ are the axial and the transverse effective thermal conductivities and $s$ is the source strength. The boundary conditions for this equation can be

- constant temperature at the inlet,

- thermally developed outlet (zero temperature gradient),

- insulation at the lateral boundaries

The initial condition can be a uniform reference temperature.

Metzger et al. [51] investigated transient heat transfer in a rectangular packed bed filled with glass spheres. Water flow from the top to the bottom in the packed bed with constant inlet temperature and the Peclet numbers below 130 were considered. The experimental setups are shown in Fig. 7(a) and 7(b). Two different configurations of the heat sources were analyzed in the study. A single wire near the inlet of the packed bed was used as a point heat source (Fig. 7(a) and a plane heat source was made by wires placed in the same plane (Fig. 7(b)). Thirteen thermocouples in the downstream measured the temperature response to a step heat input. Ordinary least squares and Gauss-Markov methods were used to estimate unknown effective thermal conductivity values in the analytical solution of Eq. (30). Monte Carlo simulations were done to assess the estimation errors. As a result of these simulations, it was claimed that the axial effective thermal conductivity has been estimated with higher accuracy whereas the lateral one has lower accuracy. Equation (31) was proposed for the axial effective thermal conductivity.

$$
\frac{k_{\text {eax }}}{k_{f}}=\frac{k_{e}}{k_{f}}+0.073 \mathrm{Pe}^{1.59}
$$

Testu et al. [52] studied the same experimental setup for the line heater shown in Fig. 7(a). Air was used as fluid phase and glass spheres and ceramic grains with internal porosity were used as the packing particles. The Peclet range between 10 and 70 were studied. Equation (27) was used to obtain the analytical temperature distribution. The medium was approximated as infinite. The ordinary least squares method was used to predict the unknown coefficients of the analytical solution with using the experimental temperature data. Both the axial and the transverse effective thermal conductivities were obtained. Some diagrams were constructed for the axial and the transverse effective thermal conductivities of the packed bed filled with spheres for various Peclet numbers. It was also claimed that the thermal equilibrium assumption is valid even for the fluid and the packing materials of different thermophysical properties.

Testu et al. [53] examined the setup in Fig. 7(a) with glass spheres. Both air and water were used as fluid. Water flow was examined for Reynolds numbers below 18 while air flow was examined for Reynolds numbers between 12 and 100. The same procedure in the study of Testu et al. [52] was followed. It was claimed that the size of the beads has no effect on the dispersion in air. The correlations were constructed for the axial and the transverse effective thermal conductivity values of water and air flows. These correlations are given in Table 6. Furthermore, another correlation, given in Table 6 , was claimed to be valid to predict the axial effective thermal conductivity values for both fluids.

\section{Discussion}

Based on the reviewed studies explained in previous section, tables are provided to compare the experimental setups and the obtained transverse and longitudinal effective thermal conductivities. Based on the explained classification, Table 1 illustrates the type of the performed experimental studies. In this table, the studies in which heat addition/removal at the lateral boundaries, heat addition at the inlet/outlet boundary, or heat addition inside the bed are listed with the corresponding reference number. As seen,
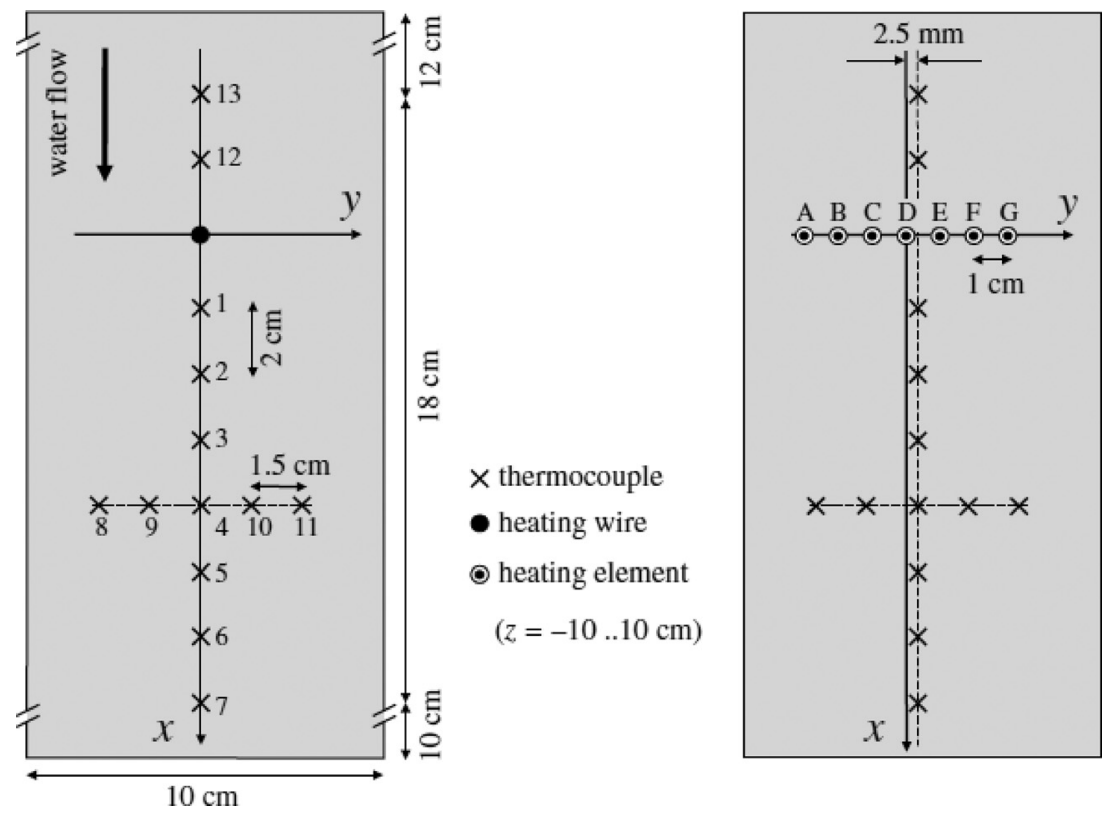

Fig. 7 Experimental setup of Metzger et al. [51] (a) Point heat source, (b) plane heat source, reprinted from Ref. [51], Copyright 2004, with permission from Elsevier 
Table 1 Experimental approaches used by various researchers to determine the effective thermal conductivity ratio

\begin{tabular}{lll}
\hline \hline $\begin{array}{l}\text { Heat Addition/removal at } \\
\text { the lateral boundaries }\end{array}$ & \multicolumn{1}{c}{$\begin{array}{c}\text { Heat addition at the } \\
\text { inlet/outlet boundary }\end{array}$} & $\begin{array}{c}\text { Heat addition } \\
\text { inside the bed }\end{array}$ \\
\hline $\begin{array}{l}\text { Smirnov et al. [23-25] } \\
\text { Thomeo and Freire [26] }\end{array}$ & $\begin{array}{l}\text { Gunn and De Souza [43] } \\
\text { Clement and Jorgensen [44] }\end{array}$ & $\begin{array}{l}\text { Metzger et al. [51] } \\
\text { Testu et al. [52,53] }\end{array}$ \\
$\begin{array}{l}\text { Demirel et al. [27] } \\
\text { Bunnell et al. [28] }\end{array}$ & Elsari and Hughes [46] \\
Wen and Ding [29] & Yagi et al. [47] & \\
Dixon and van Dongeren [30] & Vortuba et al. [48] \\
Borkink and Westerterp [32-34] & Vortmeyer and Adam [49] \\
Kwong and Smith [35] & \\
Bey and Eigenberger [36] & \\
Jorge et al. [38] & \\
Dekhtyar et al. [40] & \\
Gunn and Khalid [41] & \\
\hline \hline
\end{tabular}

Table 2 The axial and/or the radial effective thermal conductivity treatment in the reported experimental studies

\begin{tabular}{|c|c|c|c|c|c|c|}
\hline \multirow[b]{2}{*}{ Experimental studies } & \multicolumn{3}{|c|}{$\mathrm{k}_{\mathrm{eax}}$} & \multicolumn{3}{|c|}{$\mathrm{k}_{\mathrm{er}}$} \\
\hline & Calculated & Neglected & $\begin{array}{c}\text { A reported } \\
\text { correlation was used }\end{array}$ & Calculated & Neglected & $\begin{array}{c}\text { A reported } \\
\text { correlation was used }\end{array}$ \\
\hline Smirnov et al. [23-25] & & $\mathrm{X}$ & & $\mathrm{X}$ & & \\
\hline Thomeo and Freire [26] & & $\mathrm{X}$ & & $\mathrm{X}$ & & \\
\hline Demirel et al. [27] & & $\mathrm{X}$ & & $\mathrm{X}$ & & \\
\hline Bunnell et al. [28] & $\mathrm{X}$ & & & $\mathrm{X}$ & & \\
\hline Wen and Ding [29] & & & $\mathrm{X}$ & $\mathrm{X}$ & & \\
\hline Dixon and van Dongeren [30] & & & $\mathrm{X}$ & $\mathrm{X}$ & & \\
\hline Borkink and Westerterp $[32,33]$ & & $\mathrm{X}$ & & $\mathrm{X}$ & & \\
\hline Borkink and Westerterp [34] & $\mathrm{X}$ & & & $\mathrm{X}$ & & \\
\hline Kwong and Smith [35] & & $\mathrm{X}$ & & $\mathrm{X}$ & & \\
\hline Bey and Eigenberger [36] & & $\mathrm{X}$ & & $\mathrm{X}$ & & \\
\hline Jorge et al. [38] & & & $\mathrm{X}$ & $\mathrm{X}$ & & \\
\hline Dekhtyar et al. [40] & & $\mathrm{X}$ & & $\mathrm{X}$ & & \\
\hline Gunn and Khalid [41] & $\mathrm{X}$ & & & $\mathrm{X}$ & & \\
\hline Gunn and De Souza [43] & $\mathrm{X}$ & & & & $\mathrm{X}$ & \\
\hline Clement and Jorgensen [44] & $\mathrm{X}$ & & & $\mathrm{X}$ & & \\
\hline Levec and Carbonell [45] & $\mathrm{X}$ & & & $\mathrm{X}$ & & \\
\hline Elsari and Hughes [46] & $\mathrm{X}$ & & & & $\mathrm{X}$ & \\
\hline Yagi et al. [47] & $\mathrm{X}$ & & & & $\mathrm{X}$ & \\
\hline Vortuba et al. [48] & $\mathrm{X}$ & & & & $\mathrm{X}$ & \\
\hline Vortmeyer and Adam [49] & $\mathrm{X}$ & & & & $\mathrm{X}$ & \\
\hline Metzger et al. [51] & $\mathrm{X}$ & & & $\mathrm{X}$ & & \\
\hline Testu et al. $[52,53]$ & $\mathrm{X}$ & & & $\mathrm{X}$ & & \\
\hline
\end{tabular}

the most of the experimental studies were performed by using heat addition/removal at the lateral boundaries under steady condition.

Table 2 shows the treatment that was used for the determination of the axial and/or radial effective thermal conductivities. As known, the values of the effective thermal conductivities in the radial or the axial directions may be different from each other. Hence there are two unknown parameters that should be obtained from the solution of a single differential equation. The calculation of both effective thermal conductivities in the radial and the axial directions may not be easy. In many cases, the effective thermal conductivity in one of the directions may be dominant compared to the other direction. Hence one of the radial or the axial effective thermal conductivities was neglected in some studies [23-27]. However, some researchers preferred to calculate the axial effective thermal conductivity by using a proper correlation reported in the literature $[29,30,38]$. The employed correlations in those studies are given by Eq. (20), (21), and (25) in Sec. 4. Table 2 shows that the aim of the most studies was to determine the radial effective thermal conductivity, and the axial thermal conductivity was neglected or calculated from a reported correlation in the literature. Bunnell et al. [28], Borkink and Westerterp [34], Metzger et al. [51], Testu et al.
[52,53], Gunn and Khalid [41], Clement and Jorgensen [44], and Levec and Carbonell [45] determined both the axial and transverse effective thermal conductivity ratios, experimentally. Elsari and Hughes [46], Yagi et al. [47], Vortuba et al. [48], Gunn and de

Table 3 The lateral surface boundary conditions applied in studies with heat addition/removal at the lateral boundaries

\begin{tabular}{lcc}
\hline \hline $\begin{array}{l}\text { Experimental } \\
\text { studies }\end{array}$ & $\begin{array}{c}\text { Constant lateral } \\
\text { wall temperature }\end{array}$ & $\begin{array}{c}\text { Constant heat } \\
\text { flux }\end{array}$ \\
\hline $\begin{array}{l}\text { Smirnov et al. [23-25] } \\
\text { Thomeo and Freire [26] }\end{array}$ & X & \\
Demirel et al. [27] & X & X \\
Bunnell et al. [26] & X & \\
Wen and Ding [29] & X & \\
Dixon and van Dongeren [30] & X & \\
Borkink and Westerterp [32-34] & X & \\
Kwong and Smith [35] & X & \\
Bey and Eigenberger [36] & X & \\
Jorge et al. [38] & X & \\
Dekhtyar et al. [40] & & \\
Gunn and Khalid [41] & X & \\
\hline \hline
\end{tabular}


Table 4 The features of the packing particles used in the experimental studies

\begin{tabular}{|c|c|c|c|c|}
\hline \multirow[b]{2}{*}{ Experimental studies } & \multicolumn{4}{|c|}{ Particle shape } \\
\hline & Sphere & Cylinder & Raschig ring & Others \\
\hline Smirnov et al. [23] & $\begin{array}{l}\text { Steel } \\
16 \mathrm{~mm} \\
\text { Glass } \\
19 \mathrm{~mm}\end{array}$ & $\begin{array}{c}\text { Ceramic } \\
10 \mathrm{~mm}(d \text { and } l) \\
19 \mathrm{~mm}(d \text { and } l)\end{array}$ & $\begin{array}{c}\text { Ceramic } \\
14 \mathrm{~mm}\left(d_{o} \text { and } l\right) \\
\text { and } t=3.5 \mathrm{~mm} \\
\text { Copper } \\
14 \mathrm{~mm}\left(d_{o} \text { and } l\right) \\
\text { and } t=1 \mathrm{~mm}\end{array}$ & - \\
\hline Smirnov et al. [24] & - & - & - & $\begin{array}{l}\text { 4-hole and 52-hole } \\
\text { cylindrical pellets, } \\
\text { 6-spoke wheels, 3-hole } \\
\text { trilobed particles }\end{array}$ \\
\hline Smirnov et al. [25] & - & $\begin{array}{c}\text { Ceramic } \\
d=14 \mathrm{~mm} \text { and } l=9 \mathrm{~mm} \\
d=9 \mathrm{~mm} \text { and } l=19 \mathrm{~mm} \\
\text { Same with Ref. [23] }\end{array}$ & Same with Ref. [23] & $\begin{array}{c}\text { Ceramic wheel with six } \\
\text { holes, ceramic 52-hole } \\
\text { block, ceramic 4-hole } \\
\text { pellet }\end{array}$ \\
\hline Thomeo and Freire [26] & $\begin{array}{c}\text { Glass } \\
3.1 \mathrm{~mm}\end{array}$ & - & - & - \\
\hline Demirel et al. [27] & $\begin{array}{c}\text { Polystyrene } \\
48 \mathrm{~mm}, 38 \mathrm{~mm}, 29 \mathrm{~mm}\end{array}$ & - & $\begin{array}{c}\text { Polyvinyl chloride } \\
d_{p}=38.5 \mathrm{~mm}, 32.6 \mathrm{~mm}\end{array}$ & - \\
\hline Bunnell et al. [28] & - & $\begin{array}{c}\text { Alumina } \\
3.175 \mathrm{~mm}(d \text { and } l)\end{array}$ & - & - \\
\hline Wen and Ding [29] & $\begin{array}{l}\text { Glass } \\
5 \mathrm{~mm}\end{array}$ & - & - & - \\
\hline $\begin{array}{l}\text { Dixon and van Dongeren } \\
\text { [30] }\end{array}$ & $\begin{array}{l}\text { Porous ceramic, nylon, steel } \\
3.275 \mathrm{~mm}<d<24.95 \mathrm{~mm}\end{array}$ & - & - & - \\
\hline $\begin{array}{l}\text { Borkink and Westerterp } \\
{[32,33]}\end{array}$ & $\begin{array}{c}\text { Glass } \\
3.7 \mathrm{~mm} \text { and } 7.2 \mathrm{~mm}\end{array}$ & $\begin{array}{c}\text { Porous alumina } \\
d=6.4 \mathrm{~mm} \text { and } \\
l=5.2 \mathrm{~mm}\end{array}$ & $\begin{array}{c}\text { Porous alumina } \\
d_{o}=8.5 \mathrm{~mm}, t=5.4 \mathrm{~mm}, \\
l=8.6 \mathrm{~mm}\end{array}$ & - \\
\hline $\begin{array}{l}\text { Borkink and Westerterp } \\
\text { [34] }\end{array}$ & - & Same with Ref. [32] & - & - \\
\hline Kwong and Smith [35] & $\begin{array}{c}\text { Steel } \\
6.35 \mathrm{~mm} \text { and } 3.97 \mathrm{~mm} \\
\text { Alumina } \\
6.35 \mathrm{~mm} \text { and } 9.525 \mathrm{~mm}\end{array}$ & - & - & - \\
\hline Bey and Eigenberger [36] & $\begin{array}{c}\text { Ceramic } \\
4.5 \mathrm{~mm}<d<12 \mathrm{~mm} \\
\text { Glass } \\
6 \mathrm{~mm}\end{array}$ & - & $\begin{array}{c}\text { Ceramic } \\
2.8 \mathrm{~mm}<t<5.5 \mathrm{~mm} \\
5 \mathrm{~mm}<d_{o}<15 \mathrm{~mm} \\
5 \mathrm{~mm}<l<15 \mathrm{~mm}\end{array}$ & - \\
\hline Jorge et al. [38] & - & $\begin{array}{c}\text { Nickel supported alumina } \\
\begin{array}{c}d=3.54 \mathrm{~mm} \\
l=2.83 \mathrm{~mm}\end{array}\end{array}$ & - & - \\
\hline Dekhtyar et al. [40] & $\begin{array}{c}\text { Glass } \\
0.9,3.2,8.9 \mathrm{~mm}\end{array}$ & - & - & - \\
\hline Gunn and Khalid [41] & $\begin{array}{c}\text { Lead } \\
1 \mathrm{~mm}, 7 \mathrm{~mm} \\
\text { Nickel } \\
6.8 \mathrm{~mm} \\
\text { Steel } \\
6.4 \mathrm{~mm} \\
\text { Glass } \\
0.5 \mathrm{~mm}, 1.2 \mathrm{~mm}, 3 \mathrm{~mm}, 6 \mathrm{~mm}\end{array}$ & - & - & - \\
\hline Gunn and De Souza [43] & $\begin{array}{c}\text { Glass } \\
0.275,0.46,1.15,2.2,3,6 \mathrm{~mm} \\
\text { Steel } \\
\text { 3.16, } 6.32 \mathrm{~mm} \\
\text { Lead } \\
0.8 \mathrm{~mm}\end{array}$ & - & - & - \\
\hline $\begin{array}{l}\text { Clement and Jorgensen } \\
\text { [44] }\end{array}$ & - & $\begin{array}{l}\text { Pt-impregnated alumina } \\
3.7 \mathrm{~mm}(d \text { and } l)\end{array}$ & - & - \\
\hline Levec and Carbonell [45] & $\begin{array}{c}\text { Urea Formaldehyde } \\
2.5,5.5 \mathrm{~mm}\end{array}$ & - & - & - \\
\hline
\end{tabular}

031001-12 / Vol. 65, MAY 2013

Transactions of the ASME

Downloaded From: http://appliedmechanicsreviews.asmedigitalcollection.asme.org/pdfaccess.ashx?url=/data/journals/amread/927298/ on 04/10/2017 Terms of Use: http://www. 
Table 4. Continued

\begin{tabular}{|c|c|c|c|c|}
\hline \multirow[b]{2}{*}{ Experimental studies } & \multicolumn{4}{|c|}{ Particle shape } \\
\hline & Sphere & Cylinder & Raschig ring & Others \\
\hline Elsari and Hughes [46] & $\begin{array}{c}\text { Stainless steel } \\
3.17 \mathrm{~mm} \\
\text { Alumina } \\
6.4 \mathrm{~mm}\end{array}$ & 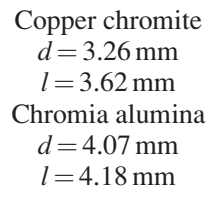 & $t=6 \mathrm{~mm}, d_{o}=l=8 \mathrm{~mm}$ & - \\
\hline Yagi et al. [47] & $\begin{array}{l}\text { Glass } \\
\text { Metal }\end{array}$ & - & & $\begin{array}{l}\text { Broken pieces of } \\
\text { limestone }\end{array}$ \\
\hline Vortuba et al. [48] & $\begin{array}{c}\text { Glass } \\
0.45,2.25,3.9,6.5 \mathrm{~mm} \\
\text { Iron } \\
5,5.15 \mathrm{~mm} \\
\text { Lead } \\
2.25 \mathrm{~mm} \\
\text { Duracryl } \\
1.3 \mathrm{~mm} \\
\text { Alumina } \\
3.4 \mathrm{~mm} \\
\text { Sand } \\
0.25 \mathrm{~mm}\end{array}$ & $\begin{array}{c}\text { Alumina } \\
d=5.4 \mathrm{~mm} \\
l=4 \mathrm{~mm}\end{array}$ & $\begin{array}{c}\text { Ceramic } \\
d_{o}=l=6.5 \mathrm{~mm} \\
t=3.5 \mathrm{~mm}\end{array}$ & $\begin{array}{c}\text { Irregular particles } \\
0.5 \mathrm{~mm}<d<2 \mathrm{~mm}\end{array}$ \\
\hline $\begin{array}{l}\text { Vortmeyer and Adam } \\
{[49]}\end{array}$ & $\begin{array}{c}\mathrm{Al}_{2} \mathrm{O}_{3} \\
5,6 \mathrm{~mm} \\
\text { Plastic } \\
6 \mathrm{~mm} \\
\text { Glass } \\
5,8 \mathrm{~mm} \\
\text { Steel } \\
2<d<10 \mathrm{~mm} \\
\text { Bronze } \\
6 \mathrm{~mm} \\
\text { Brass } \\
6 \mathrm{~mm}\end{array}$ & - & - & - \\
\hline Metzger et al. [51] & $\begin{array}{l}\text { Glass } \\
2 \mathrm{~mm}\end{array}$ & - & - & - \\
\hline Testu et al. [52] & $\begin{array}{l}\text { Glass } \\
2 \mathrm{~mm}\end{array}$ & - & - & - \\
\hline Testu et al. [53] & $\begin{array}{l}\text { Glass } \\
2 \mathrm{~mm}\end{array}$ & - & - & - \\
\hline
\end{tabular}

Note: $d, d_{o}$, and $d_{p}$ are particle, outer, and equivalent diameters while $l$ and $t$ are the length and the thickness, respectively.

Souza [43] and Vortmeyer and Adam [49] performed the experimental study to determine only the axial effective thermal conductivity. A considerable amount of researchers ignored one of the two effective thermal conductivities.

Table 3 displays the comparison of the boundary conditions applied at the lateral boundaries of the packed beds used in the first type of the experimental methods (Heat addition/removal at the lateral boundaries). At the most of the studies, the lateral boundary was kept at a constant temperature by flowing water or steam in a jacket surrounded this boundary. However, Demirel et al. [27] and Dekhtyar et al. [40] used constant heat flux at the lateral boundaries of the packed bed to generate temperature gradient in radial direction inside the bed.

Table 4 compares the shape, size and materials of the packing particles in the reported experiments. The first column refers to the researcher and the corresponding reference number in this paper, the second, third, and fourth columns refer to the shape, size and material of the employed particles which can be sphere, cylinder, or Raschig rings, respectively. The unclassified particle shapes are mentioned in the fifth column. In most of the studies, the particles with spherical shape were used. The size of the employed spherical particles widely changed from $0.275 \mathrm{~mm}$ to $48 \mathrm{~mm}$. Then, the cylindrical particles were mostly used to determine the effective thermal conductivity for the packed beds. The diameter and length of the cylinder particles changed between $3.175 \mathrm{~mm}$ and $19 \mathrm{~mm}$. Besides the studies with sphere and cylinder particles, some researchers preferred to use Raschig ring which is hollow cylinder. Based on the reported information, the inner and the outer diameters of Raschig rings changed from 2 to $13 \mathrm{~mm}$, and 5 to $15 \mathrm{~mm}$, respectively. The length of Raschig rings varied from 5 to $15 \mathrm{~mm}$. The materials of the particles were also very different. The glass materials were used in almost $60 \%$ of the studies given in this review. Glass is followed by steel, alumina and ceramic materials. Copper, polystyrene, polyvinyl chloride, nylon and tungsten are the other materials used in the experiments.

The dimensions and the shapes of the packed beds, the ratios of the tube to particle diameters and employed fluid phases are compared in Table 5. The cylindrical packed beds were used widely. The use of the cylindrical beds provides some advantages such as the simplification of the macroscopic energy equation and also the checking of the temperature measurements at different points in 


\begin{tabular}{|c|c|c|c|c|}
\hline \multirow[b]{2}{*}{ Experimental studies } & \multicolumn{2}{|c|}{ Bed shape } & \multirow{2}{*}{$\begin{array}{l}\text { Tube-to-particle } \\
\text { diameter ratio }\end{array}$} & \multirow[b]{2}{*}{ Employed fluid } \\
\hline & Cylindrical & Rectangular & & \\
\hline Smirnov et al. [23-25] & $\begin{array}{c}D_{i}=84 \mathrm{~mm} \\
L=1130 \mathrm{~mm} \\
(330 \mathrm{~mm} \text { heating, } \\
150 \mathrm{~mm} \text { calming, } \\
650 \mathrm{~mm} \text { cooled test sections })\end{array}$ & - & Btw 4 and 5.25 & Air \\
\hline Thomeo and Freire [26] & $\begin{array}{c}D_{i}=57 \mathrm{~mm} \\
L=346 \mathrm{~mm} \\
(246 \mathrm{~mm} \text { inlet, } \\
100 \mathrm{~mm} \text { cooling sections })\end{array}$ & - & 18.4 & Air \\
\hline Demirel et al. [27] & - & $\begin{array}{l}L 1600 \mathrm{~mm} \\
H 100 \mathrm{~mm} \\
w 400 \mathrm{~mm}\end{array}$ & - & Air \\
\hline Bunnell et al. [28] & $\begin{array}{l}D_{i}=50.8 \mathrm{~mm} \\
L=965.2 \mathrm{~mm}\end{array}$ & - & 16 & Air \\
\hline Wen and Ding [29] & $\begin{array}{c}D_{i}=41 \mathrm{~mm} \\
L=1100 \mathrm{~mm}\end{array}$ & - & 8.2 & Air \\
\hline Dixon and van Dongeren [30] & $\begin{array}{c}D_{i}=26.2,50.3,74.9,99.8 \mathrm{~mm} \\
602 \mathrm{~mm}<L<640 \mathrm{~mm} \\
(450-475 \mathrm{~mm} \text { test } \\
152-165 \mathrm{~mm} \text { calming sections })\end{array}$ & - & 4 and 8 & Air \\
\hline Borkink and Westerterp $[32,33]$ & $\begin{array}{c}D_{i}=49.9,63.5,99 \mathrm{~mm} \\
L=1300 \mathrm{~mm}\end{array}$ & - & $\sim$ btw 7 and 27 & Air \\
\hline Borkink and Westerterp [34] & Same with Ref. [32] & - & Btw 8 and 17 & Air \\
\hline Kwong and Smith [35] & $D_{i}=50.8,101.6 \mathrm{~mm}$ & - & Btw 5 and 26 & $\begin{array}{c}\text { Air } \\
\text { Ammonia }\end{array}$ \\
\hline Bey and Eigenberger [36] & - & $\begin{array}{l}H=50 \mathrm{~mm} \\
L=60 \mathrm{~mm}\end{array}$ & Btw 3.3 and 11 & Air \\
\hline Jorge et al. [38] & $\begin{array}{c}D_{i}=60 \mathrm{~mm} \\
L=650 \mathrm{~mm} \\
\text { (250 mm calming, } \\
400 \mathrm{~mm} \text { heating } \\
\text { test sections) }\end{array}$ & - & $\sim 16$ & Air \\
\hline Dekhtyar et al. [40] & $\begin{array}{l}D_{i}=52 \mathrm{~mm} \\
L=531 \mathrm{~mm}\end{array}$ & - & Btw 5.8 and 58 & $\begin{array}{c}\text { Water } \\
47 \% \text { aqueous } \\
\text { solution of glycerin }\end{array}$ \\
\hline Gunn and Khalid [41] & $\begin{array}{c}D_{i}=95.25 \mathrm{~mm} \\
L=304.8 \mathrm{~mm}\end{array}$ & - & Btw 13.5 and 190.5 & Air \\
\hline Gunn and De Souza [43] & $L=30$ and $60 \mathrm{~mm}$ & - & - & Air \\
\hline Clement and Jorgensen [44] & $\begin{array}{l}D_{i}=98 \mathrm{~mm} \\
L=500 \mathrm{~mm}\end{array}$ & - & $\sim 26$ & Air \\
\hline Levec and Carbonell [45] & - & $\begin{array}{c}H=210 \mathrm{~mm} \\
L=1060 \mathrm{~mm} \\
w=210 \mathrm{~mm}\end{array}$ & - & Water \\
\hline Elsari and Hughes [46] & $\begin{array}{l}D_{i}=25 \mathrm{~mm} \\
L=230 \mathrm{~mm}\end{array}$ & - & Btw 3.9 and 8 & Air, $\mathrm{N}_{2}, \mathrm{CO}_{2}$ \\
\hline Yagi et al. [47] & $D_{i}=50,68 \mathrm{~mm}$ & - & - & Air \\
\hline Vortuba et al. [48] & $D_{i}=26 \mathrm{~mm}$ & - & Btw 3.85 and 104 & Air, $\mathrm{O}_{2}, \mathrm{~N}_{2}$ \\
\hline Vortmeyer and Adam [49] & $\begin{array}{c}D_{i}=86,139,200 \mathrm{~mm} \\
L=310 \mathrm{~mm}\end{array}$ & - & Btw 8.6 and 100 & Air, $\mathrm{CO}_{2}, \mathrm{He}$ \\
\hline Metzger et al. [51] & - & $\begin{array}{l}L=400 \mathrm{~mm} \\
H=100 \mathrm{~mm} \\
w=200 \mathrm{~mm}\end{array}$ & - & Water \\
\hline Testu et al. [52] & - & Same with Ref. [51] & - & Air \\
\hline Testu et al. [53] & - & Same with Ref. [51] & - & Water/Air \\
\hline
\end{tabular}

Note: $D_{i}$ is the inner diameter, $L$ is the length, $H$ is the height and $w$ is the width of the tubes.

031001-14 / Vol. 65, MAY 2013

Transactions of the ASME

Downloaded From: http://appliedmechanicsreviews.asmedigitalcollection.asme.org/pdfaccess.ashx?url=/data/journals/amread/927298/ on 04/10/2017 Terms of Use: http://www. 


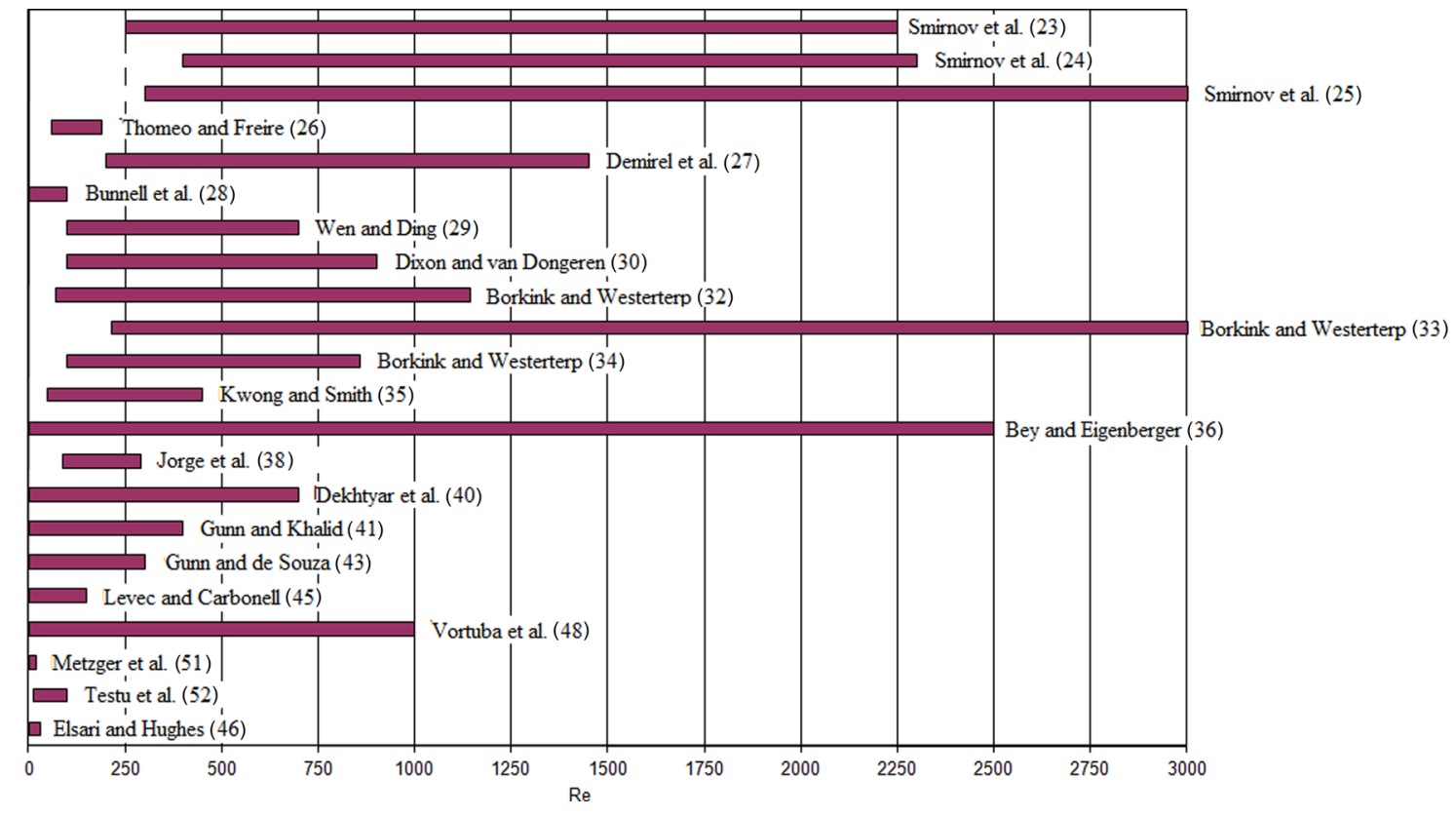

Fig. 8 The Reynolds number ranges in the reported experimental studies

the same arm location but at different angles. By this way, an axisymmetrical flow is achieved and by comparison of the temperature at different angles, the accuracy of the measured temperature can be checked. The inner diameters of the packed beds changed from 25 to $200 \mathrm{~mm}$. The length of bed also varied between 30 and $1300 \mathrm{~mm}$. Generally, the lengths of the packed beds were kept much longer than its diameter to extract the end effects. Some of the researchers preferred to perform the experimental studies on the rectangular packed beds. The length and the height of the rectangular beds varied between 60 to $1600 \mathrm{~mm}$, and 50 to $210 \mathrm{~mm}$, respectively. The width of the beds changed from 200 to $400 \mathrm{~mm}$. As seen from Table 5, the tube-to-particle diameter ratios changed between 3.3 and 190.5. Air was the most common fluid in the experimental studies of the thermal dispersion. The other fluids used in the researches were water, glycerol, glycerin, ammonia, nitrogen and carbon dioxide.

Figure 8 shows the ranges of the studied Reynolds numbers by different researchers. A wide range of Reynolds numbers was studied. Most of the researchers preferred to study on the Reynolds numbers less than 1000 . This may be due to the possibility of the occurrence of turbulent flow. The solution of the macroscopic turbulent energy equation in the voids between the particles is not easy because in addition to unknown effective thermal conductivities in different directions, the turbulent thermal diffusivity should also be predicted.

Based on the performed experimental studies, the proposed effective thermal conductivity correlations are shown in Table 6 . The first column shows the researchers and the reference numbers. The proposed correlations are given in the second column. The value of the constants used in the suggested correlations and the conditions, for which the suggested correlations are valid, are presented in the third column. This table does not include all the works reviewed in the present paper since in some of the reviewed experimental studies, no relation for the determination of the effective thermal conductivity was proposed and the results were presented via graphics. In 15 of the studies (about half of studies), relations for the determination of the effective thermal conductivity were suggested. The value of effective thermal conductivity ratio is calculated based on the flow and structural parameters such as Reynolds (or Peclet) number and the particle shape and material. Most of the proposed relations involve Reynolds number and the equivalent thermal conductivity of the bed while some researchers included Prandtl number and porosity in their pro- posed correlations. Equation (16) indicates that the effective thermal conductivity can be written as the summation of the equivalent and thermal dispersion conductivities. Generally, the first term in the correlations shows the effect of the equivalent thermal conductivity. As can be seen from Eq. (13), the value of the equivalent thermal conductivity may be constant for a packed bed. The second term of the correlations shows the thermal dispersion conductivity which changes with Reynolds (or Peclet) number. Thus, a suggested correlation for the determination of effective thermal conductivity should include these conductivities. Some researchers presented the ratio of equivalent thermal conductivity to the fluid thermal conductivity in their suggested correlations. Hence, the value of the equivalent thermal conductivity should be calculated by an equation. Other researchers preferred to give a constant value for the ratio of equivalent thermal conductivity to the thermal conductivity of the fluid in their correlations.

Table 6 shows that the correlations proposed for the determination of the radial or axial effective thermal conductivity are either based on Reynolds or Peclet numbers. In the all suggested relations, a proportional relation exists between the effective thermal conductivity and Reynolds number. By increase of Reynolds number, the thermal dispersion becomes more influential on the heat transfer in the packed bed, compared to the molecular heat diffusion. Generally, the reported studies in the literature were performed by using a fluid (water, or air). Hence, the inclusion of Prandtl number in some correlations may be arguable since the main variable parameter has been Reynolds number and Prandtl number has been fixed. The inclusion of Prandtl number in the correlations may be more meaningful if the experiments are performed for different fluids. There is a limited number of conducted with two or more different fluid. Testu et al. [53], Vortuba et al. [48], and Vortmeyer and Adam [38] suggested correlations by using different fluids. However, it seems that more studies have to be performed to include the effects of Prandtl number and find a correlation which will be valid for wide range of fluids.

In Fig. 9, the comparison of the change of radial (or transverse) effective thermal conductivity ratios, found by using the proposed correlations in Table 6, with Reynolds number is shown. The radial effective thermal conductivity ratios are calculated for air. The variation of the radial effective thermal conductivity with Reynolds number for sphere, cylinder, and Raschig ring particle beds with Reynolds number are shown in Fig. $9(a), 9(b)$, and $9(c)$, respectively. The range of the experimented Reynolds numbers is 


\begin{tabular}{|c|c|c|}
\hline Experimental studies & Correlation & Constant values and validation conditions \\
\hline Smirnov et al. [23] & $\frac{k_{e r}}{k_{f}}=\frac{k_{e}}{k_{f}}+K \cdot \operatorname{Re} \operatorname{Pr}$ & $\begin{array}{c}K=0.089 \text { for steel spheres } \\
K=0.091 \text { for glass spheres } \\
K=0.146 \text { for } 10 \mathrm{~mm} \text { diameter ceramic cylinders } \\
K=0.14 \text { for } 19 \mathrm{~mm} \text { diameter ceramic cylinders } \\
K=0.16 \text { for } 3.5 \mathrm{~mm} \text { diameter ceramic Raschig rings } \\
K=0.21 \text { for } 1 \mathrm{~mm} \text { diameter copper Raschig rings }\end{array}$ \\
\hline Smirnov et al. [24] & Same correlation with Ref. [23] & $\begin{array}{c}K=0.14 \text { for ceramic } 52 \text { hole block } \\
K=0.2 \text { for ceramic } 4 \text {-hole pellet } \\
K=0.17 \text { for ceramic } 6 \text {-spoke wheel } \\
K=0.24 \text { for ceramic } 3 \text {-hole trilobed particle }\end{array}$ \\
\hline Smirnov et al. [25] & Same correlation with Ref. [23] & $\begin{array}{l}K=0.14 \text { for ceramic cylinder of } D=14 \mathrm{~mm} \text { and } \\
\qquad L=9 \mathrm{~mm} \\
K=0.16 \text { for ceramic cylinder of } D=9 \mathrm{~mm} \text { and } \\
L=19 \mathrm{~mm} \\
K=0.17 \text { for ceramic wheel } w=\text { thickness } 2 \mathrm{~mm} \\
K=0.23 \text { for ceramic wheel } w=\text { thickness } 1 \mathrm{~mm}\end{array}$ \\
\hline
\end{tabular}

Demirel et al. [27]

Bunnell et al. [28]

Borkink and Westerterp [32]

Bey and Eigenberger [36]

Jorge et al. [38]

Dekhtyar et al. [40]

Metzger et al. [51]

Testu et al. [53]

Elsari and Hughes [35]

$$
\begin{aligned}
& \frac{k_{e r}}{k_{f}}=2.894+0.068 \mathrm{Re} \\
& \frac{k_{e r}}{k_{f}}=10.432+0.0481 \mathrm{Re}
\end{aligned}
$$

$$
\frac{k_{e a x}}{k_{f}}=\frac{k_{e r}}{k_{f}}=5.0+0.061 \mathrm{Re}
$$

$$
\frac{k_{e r}}{k_{f}}=\frac{k_{e}}{k_{f}}+\frac{\mathrm{Pe}}{B}
$$

$$
\begin{gathered}
\frac{k_{e r}}{k_{f}}=\frac{k_{e}}{k_{f}}+\frac{\mathrm{Pe}}{K_{r}} \\
\frac{k_{e r}}{k_{f}}=\frac{k_{e}}{k_{f}}+0.16 \operatorname{Re} \operatorname{Pr}
\end{gathered}
$$

$$
\begin{gathered}
\frac{k_{e r}}{k_{f}}=0.083 \operatorname{Re} \operatorname{Pr} \\
\frac{k_{e a x}}{k_{f}}=\frac{k_{e}}{k_{f}}+0.073 \mathrm{Pe}^{1.59}
\end{gathered}
$$

$$
\begin{aligned}
\frac{k_{e a x}}{k_{f}} & =\frac{k_{e}}{k_{f}}+1.61 \mathrm{Re}^{1.59} \\
\frac{k_{e a x}}{k_{f}} & =\frac{k_{e}}{k_{f}}+0.126 \mathrm{Pe}^{1.45} \\
\frac{k_{e a x}}{k_{e}}= & 1+\frac{k_{f}}{k_{e}} \varepsilon(1-\varepsilon) \operatorname{Re}^{1.5} \\
& \times\left[\frac{8.87(\operatorname{Pr}-0.7)-0.543(\operatorname{Pr}-7.02)}{6.32}\right] \\
\frac{k_{e t r}}{k_{f}} & =6.4+0.113 \mathrm{Pe} \\
\frac{k_{e t r}}{k_{f}} & =\frac{k_{e}}{k_{f}}+0.04 \mathrm{Pe}
\end{aligned}
$$

$$
\begin{aligned}
& \frac{k_{\text {eax }}}{k_{f}}=7.24+8.49 \mathrm{Re} \\
& \frac{k_{\text {eax }}}{k_{f}}=4.25+7.20 \mathrm{Re}
\end{aligned}
$$

For polyvinyl chloride Raschig rings

For polystyrene spheres

For alumina cylinders

$$
\begin{gathered}
k_{e} / k_{f}=4.7, \text { and } B=8.8 \text { for } 3.7 \mathrm{~mm} \text { diameter spheres, } \\
\quad \text { and } N=13.5 \\
k_{e} / k_{f}=6.2 \text { and } B=10.9 \text { for } 7.2 \mathrm{~mm} \text { diameter spheres } \\
\text { and } 7<N<14 \\
k_{e} / k_{f}=4, B=7.6 \text { for cylinders, and } 8<N<17 \\
k_{e} / k_{f}=4.5 \text { and } B=4.2 \text { for Raschig rings } \\
\text { and } 8 \leq N \leq 16 \\
N \text { is number of particles on a diameter }
\end{gathered}
$$

$K_{r}$ is empirical constant and its values were given in graphics

For nickel supported on alumina cylinders

$$
\begin{gathered}
\text { where } \\
\frac{k_{e}}{k_{f}}=\left(\frac{k_{s}}{k_{f}}\right)^{n} \\
n=0.28-0.757 \log (\varepsilon)-0.057 \log \left(\frac{k_{s}}{k_{f}}\right)[54]
\end{gathered}
$$

For glass spheres

For water and glass spheres

$$
k_{e} \cong 0.86 \mathrm{~W} / \mathrm{mK}
$$

Water, $0<\operatorname{Re}<18$

Air, $12<\operatorname{Re}<100$

Both water and air

Air, $12<\operatorname{Re}<130$

Water, $0.5<\operatorname{Re}<18$

Steel ball bearings

Copper chromite cylinder 
Table 6. Continued

\begin{tabular}{|c|c|c|}
\hline Experimental studies & Correlation & Constant values and validation conditions \\
\hline & $\begin{array}{l}\frac{k_{\text {eax }}}{k_{f}}=3.24+6.47 \mathrm{Re} \\
\frac{k_{\text {eax }}}{k_{f}}=9.68+3.21 \mathrm{Re} \\
\frac{k_{\text {eax }}}{k_{f}}=8.63+3.12 \mathrm{Re}\end{array}$ & $\begin{array}{l}\text { Chromia alumina cylinder } \\
\text { Alumina hollow cylinder } \\
\text { Alumina spheres }\end{array}$ \\
\hline Yagi et al. [36] & $\frac{k_{e a x}}{k_{f}}=\frac{k_{e}}{k_{f}}+\delta \mathrm{Pe}$ & $\begin{array}{c}\delta=0.8 \text { for glass beads } \\
\delta=0.7 \text { for metal spheres }\end{array}$ \\
\hline \multirow[t]{2}{*}{ Vortmeyer and Adam [38] } & $\frac{k_{e a x}}{k_{f}}=\frac{k_{e}}{k_{f}}+\frac{g \nu \operatorname{Re} / d_{p}}{1+h \nu \operatorname{Re} / d_{p}}$ & $\begin{array}{c}g=1420,1060,600 \mathrm{~s} / \mathrm{m}, \text { and } h=70,96,110 \mathrm{~s} / \mathrm{m} \text { for } \\
\text { metal, glass, and catalyst, respectively } \\
\nu \text { is kinematic viscosity }\end{array}$ \\
\hline & $\frac{k_{e a x}}{k_{f}}=\frac{k_{e}}{k_{f}}+\frac{k v \operatorname{Re} \operatorname{Pr} / d_{p}}{1+p v \operatorname{Re} / d_{p}}$ & $\begin{array}{c}\text { For glass spheres and any gases } \\
k \text { and } p \text { are experimental parameters found for } \mathrm{CO}_{2} \text {, air } \\
\text { and } \mathrm{He}\end{array}$ \\
\hline Vortuba et al. [48] & $\frac{k_{\text {eax }}}{G c_{p} d_{p}}=\frac{k_{e} / k_{f}}{\operatorname{Re} \operatorname{Pr}}+\frac{14.5}{d_{p}\left(1+\frac{C_{3}}{\operatorname{Re} \operatorname{Pr}}\right)}$ & $G$ is mass flow rate, $C_{3}$ is experimental parameter \\
\hline
\end{tabular}

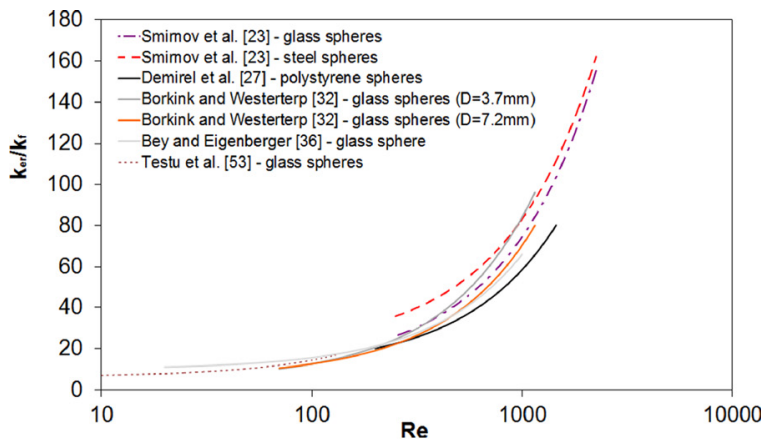

(a)

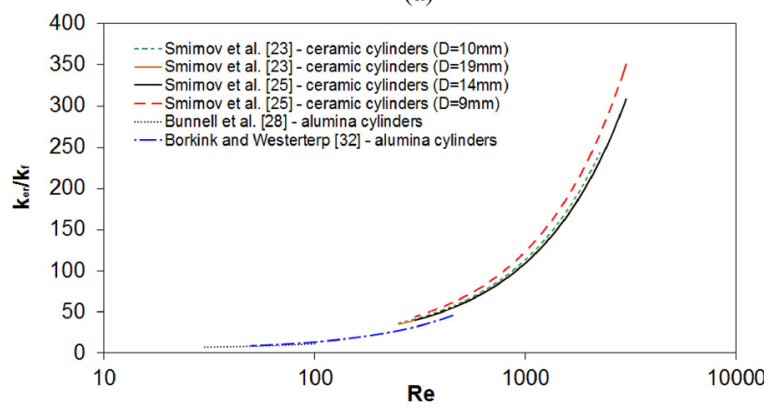

(b)

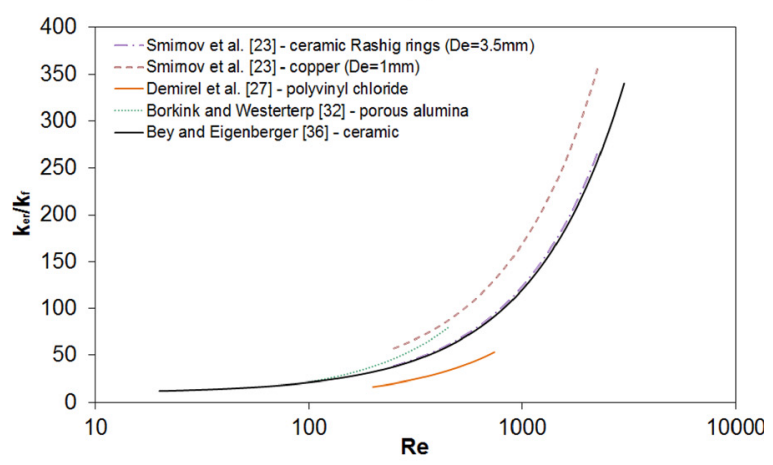

(c)

Fig. 9 The comparison of reported correlations for determination of radial effective thermal conductivity ratio (a) spherical particle bed, (b) cylindrical particle bed, (c) Raschig ring particle bed considered in this diagram and the results are not extended out of the reported range. Figure $9(a)$ shows the variation of the radial effective thermal conductivity ratio with Reynolds number for the beds with the spherical particles. The experimental results of the beds with the spherical particles have good agreement with each other. As can be seen from the figure, the obtained experimental results for low Reynolds numbers (i.e. $\operatorname{Re}<400$ ) have excellent agreement. However, by the increase of Reynolds number, the consistency between the results decreases. This might be due to the occurrence of turbulent flow and the increasing effects of the surface roughness of the particles as well as the particle arrangement in the packed bed. Figure $9(b)$ shows the change of the radial effective thermal conductivity ratio for the cylindrical particle beds. Four correlations on the cylindrical particle beds could be found in the literature. A good consistency between the correlations can be observed. Finally, Fig. 9(c) illustrates the change of $k_{e r} / k_{f}$ with Re for Raschig ring particles. The correlations of different studies do not align with each other. This difference between the results of the correlations might be due to the different shapes of the experimented Raschig rings and the different bed porosities because of the different thicknesses of Raschig rings. Bey and Eigenberger [36] performed experiments with thick Raschig rings $\left(d_{o}=5\right.$, $d_{i}=2.2$, and $L=5 \mathrm{~mm}$ ). However, Sminov et al. [23] used relatively thin Raschig rings $\left(d_{o}=14, d_{i}=13\right.$, and $\left.L=14 \mathrm{~mm}\right)$.

The comparison between the axial effective thermal conductivity correlations cannot be made because of the diversity of the employed packing particles and fluids.

\section{Conclusion}

The experimental studies that have been performed for the determination of the transverse and the axial thermal dispersion conductivities are classified into three groups: (1) heat addition/removal at the lateral boundaries, (2) heat addition at the inlet/outlet boundary and, (3) heat addition inside the bed. Our literature review shows that the most of the studies were performed with heat addition/removal at the lateral boundaries under steady state conditions. The transient studies have been performed by using the heat addition at the inlet/outlet boundary for the determination of axial thermal dispersion.

Generally, the procedure is almost standardized for all these experimental approaches. A temperature gradient is generated in the bed. The temperature is measured at various locations in the 
packed bed. An analytical (or rarely numerical) solution for the macroscopic energy equation is obtained under the imposed boundary/initial conditions. Then, the comparison between the experimental and theoretical values of the temperature distribution in the bed yields the effective thermal conductivity.

Heat addition/removal at constant temperature lateral boundaries was mostly preferred in the literature due to the ease of application, probably. The spherical particles were favorable shape in the performed studies and air was mostly used. In most of the studies, the shape of the bed was cylindrical to provide an axisymmetrical condition. The studies were performed for a wide range of particle-based Reynolds numbers. It is important to note that no laminar/turbulent distinction was taken into account for the suggested correlations. Peclet number is the main independent parameter in the suggested correlations, however there are correlations established based on Reynolds number only.

The diagrams showing the variation of the radial effective thermal conductivity ratio with Reynolds number for air reveal that there are good agreements between the results of different correlations for the spherical and the cylindrical particle beds. However, the same agreement is not observed for Raschig ring particles since the shape of Raschig rings depends on three parameters as the inner and outer diameters and the thickness.

The present study indicates that although the thermal dispersion conductivity plays an important role in the convective heat transfer in porous media, the number of the performed experimental studies on the thermal dispersion is limited. The proposed correlations are also limited and mostly established for the spherical particle beds.

\section{Nomenclature}

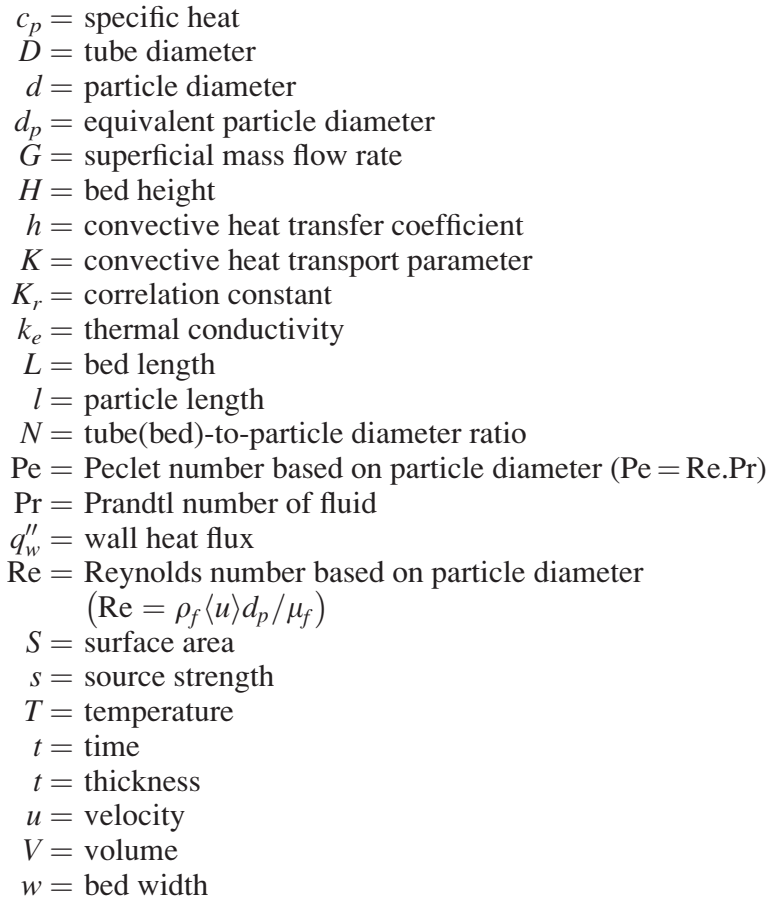

\section{Greek Symbols}

$$
\begin{aligned}
\varepsilon & =\text { porosity } \\
\mu & =\text { viscosity } \\
\rho & =\text { density } \\
\varphi & =\text { any variable } \\
\langle\rangle & =\text { volume average }
\end{aligned}
$$

\section{Subscripts}

$$
\begin{aligned}
c & =\text { characteristic } \\
\text { dis } & =\text { thermal dispersion }
\end{aligned}
$$

$e=$ equivalent

eax $=$ axial (longitudinal) effective thermal conductivity

eff $=$ effective

er $=$ radial (transverse) effective thermal conductivity

etr $=$ transverse effective thermal conductivity

$f=$ fluid

$i=$ inner

$o=$ outer

$s=$ solid

$w=$ wall

\section{References}

[1] Nakayama, A., 1995, PC-Aided Numerical Heat Transfer and Convective Flow, CRC Press, Boca Raton, FL

[2] Kaviany, M., 1995, Principles of Heat Transfer in Porous Media, 2nd ed., Springer-Verlag, New York.

[3] Ochoa-Tapia, J. A., and Whitaker, S., 1995, "Momentum Transfer at the Boundary Between a Porous Medium and a Homogeneous Fluid-I. Theoretical Development," Int. J. Heat Mass Transfer, 38(14), pp. 2635-2646.

[4] Ochoa-Tapia, J. A., and Whitaker, S., 1995, "Momentum Transfer at the Boundary Between a Porous Medium and a Homogeneous Fluid-II. Comparison with Experiment," Int. J. Heat Mass Transfer, 38(14), pp. 2647-2655.

[5] Ochoa-Tapia, J. A., and Whitaker, S., 1997, "Heat Transfer at the Boundary Between a Porous Medium and a Homogeneous Fluid,” Int. J. Heat Mass Transfer, 40(11), pp. 2691-2707.

[6] Whitaker, S., 1999, The Method of Volume Averaging, Kluwer Academic, Dordrecht, The Netherlands.

[7] Quintard, M., and Whitaker, S., 1995, "Local Thermal Equilibrium for Transient Heat Conduction: Theory and Comparison With Numerical Experiments," Int. J. Heat Mass Transfer, 38(15), pp. 2779-2796.

[8] Hsu, C. T., Cheng, P., and Wong, K. W., 1994, "Modified Zehner-Schlunder Models for Stagnant Thermal Conductivity of Porous Media,” Int. J. Heat Mass Transfer, 37(17), pp. 2751-2759.

[9] Hsu, C. T., 2000, "Conduction in Porous Media," Handbook of Porous Media, K. Vafai, ed., CRC Press, Boca Raton, FL.

[10] Olives, R., and Mauran, S., 2001, "A Highly Conductive Porous Medium for Solid-Gas Reactions: Effect of the Dispersed Phase on the Thermal Tortuosity," Transp. Porous Media, 43, pp. 377-394.

[11] Kuwahara, F., and Nakayama, A., 1999, "Numerical Determination of Thermal Dispersion Coefficients Using a Periodic Structure," ASME J. Heat Transfer, 121, pp. 160-163.

[12] Kuwahara, F., Nakayama, A., and Koyama, H., 1996, "A Numerical Study of Thermal Dispersion in Porous Media," J. Heat Transfer, 118, pp. 756-761.

[13] Xu, J., Lu, T. J., Hodson, H. P., and Fleck, N. A., 2010, "Analysis of Thermal Dispersion in an Array of Parallel Plates with Fully-Developed Laminar Flow," Int. J. Heat Fluid Flow, 31, pp. 57-69.

[14] Pedras, M. H. J., and de Lemos, M. J. S., 2008, "Thermal Dispersion in Porous Media as a Function of the Solid-Fluid Conductivity Ratio," Int. J. Heat Mass Transfer, 51, pp. 5359-5367.

[15] Quintard, M., Kaviany, M., and Whitaker, S., 1997, "Two-Medium Treatment of Heat Transfer in Porous Media: Numerical Results for Effective Properties," Adv. Water Resour., 20, pp. 77-94.

[16] Hsu, C. T., and Cheng, P., 1988, "Closure Schemes of the Macroscopic Energy Equation for Convective Heat Transfer in Porous Media," Int. Commun. Heat Mass Transfer, 15, pp. 689-703.

[17] Hsu, C. T., and Cheng, P., 1990, "Thermal Dispersion in Porous Media," Int. J. Heat Mass Transfer, 33(8), pp. 1587-1597.

[18] Jeong, N., and Choi, D. H., 2011, "Estimation of the Thermal Dispersion in a Porous Medium of Complex Structures Using a Lattice Boltzmann Method," Int. J. Heat Mass Transfer, 54, pp. 4389-4399.

[19] Pathak, M. G., and Ghiaasiaan, S. M., 2011, "Convective Heat Transfer and Thermal Dispersion During Laminar Pulsating Flow in Porous Media," Int. J. Thermal Sci., 50, pp. 440-448.

[20] Alshare, A. A., Strykowski, P. J., and Simon, T. W., 2010, "Modeling of Unsteady and Steady Fluid Flow, Heat Transfer and Dispersion in Porous Media Using Unit Cell Scale,” Int. J. Heat Mass Transfer, 53, pp. 2294-2310.

[21] Pinson, F., Gregoire, O., Quintard, M., Prat, M., and Simonin, O., 2007, "Modeling of Turbulent Heat Transfer and Thermal Dispersion for Flows in Flat Plate Heat Exchangers,” Int. J. Heat Mass Transfer, 50, pp. 1500-1515.

[22] Quintard, M., and Whitaker, S., 1993, "Transport in Ordered and Disordered Porous Media: Volume-Averaged Equations, Closure Problems, and Comparison with Experiment," Chem. Eng. Sci., 48(14), pp. 2537-2564.

[23] Smirnov, E. I., Muzykantov, A. V., Kuzmin, V. A., Kronberg, A. E., and Zolotarskii, I. A., 2003, "Radial Heat Transfer in Packed Beds of Spheres, Cylinders and Raschig Rings-Verification of Model With a Linear Variation of $\lambda$ er in the Vicinity of the Wall," Chem. Eng. J., 91, pp. 243-248.

[24] Smirnov, E. I., Muzykantov, A. V., Kuzmin, V. A., Zolotarskii, I. A., Koning, G. W., and Kronberg, A. E., 2003, "Radial Heat Transfer in Packed Beds of Shaped Particles," Chemistry for Sustainable Development, 11, pp. 293-296.

[25] Smirnov, E. I., Kuzmin, V. A., and Zolotarskii, I. A., 2004, "Radial Thermal Conductivity in Cylindrical Beds Packed by Shaped Particles," Chem. Eng. Res. Des., 82(A2), pp. 293-296.

[26] Thomeo, J. C., and Freire, J. T., 2000, "Heat Transfer in Fixed Bed: A Model Non-Linearity Approach,” Chem. Eng. Sci., 55, pp. 2329-2338. 
[27] Demirel, Y., Sharma, R. N., and Al-Ali, H. H., 2000, "On the Effective Heat Transfer Parameters in a Packed Bed,” Int. J. Heat Mass Transfer, 43, pp. 327-332.

[28] Bunnell, D. G., Irvin, H. B., Olson, R. W., and Smith, J. M., 1949, "Effective Thermal Conductivities in Gas-Solid Systems," Ind. Eng. Chem., 41(9), pp. 1977-1998

[29] Wen, D., and Ding, Y., 2006, "Heat Transfer of Gas Flow Through a Packed Bed," Chem. Eng. Sci., 61, pp. 3532-3542.

[30] Dixon, A. G., and van Dongeren, J. H., 1998, "The Influence of the Tube and Particle Diameters at Constant Ratio on Heat Transfer in Packed Beds," Chem. Eng. Process., 37, pp. 23-32.

[31] Wakao, N., Kaguei, S., and Nagai, H.,1978, "Effective Diffusion Coefficient for Fluid Species Reacting With Fist Order Kinetics in Packed Bed Reactors and Discussion on Evaluation of Catalyst Effectiveness Factors," Chem. Eng. Sci., 33, pp. 183-187.

[32] Borkink, J. G. H., and Westerterp, K. R., 1992, "Influence of Tube and Particle Diameter on Heat Transport in Packed Beds," AIChE J., 38(5), pp. 703-715.

[33] Borkink, J. G. H., and Westerterp, K. R., 1992, "Determination of Effective Heat Transport Coefficients for Wall-Cooled Packed Beds," Chem. Eng. Sci., 47(9), pp. 2337-2342.

[34] Borkink, J. G. H., and Westerterp, K. R., 1992, "Significance of Axial Heat Dispersion for the Description of Heat Transport in Wall-Cooled Packed Beds," Chem. Eng. Tech., 15, pp. 371-384.

[35] Kwong, S. S., and Smith, J. M., 1957, "Radial Heat Transfer in Packed Beds," Ind. Eng. Chem., 49(5), pp. 894-903.

[36] Bey, O., and Eigenberger, G., 2001, "Gas Flow and Heat Transfer Through Catalyst Filled Tubes," Int. J. Therm. Sci., 40, pp. 152-164.

[37] Bauer, R., and Schlünder, E. U., 1977, "Die Effektive Radiale Wärmeleitfähigkeit Gasdurchströmter Schöttungen," Verfahrenstechnik, 11(10), pp. 605-613.

[38] Jorge, L. M. M., Jorge, R. M. M., and Giudici, R., 2010, "Experimental and Numerical Investigation of Dynamic Heat Transfer Parameters in Packed Bed," Heat Mass Transfer, 46, pp. 1355-1365.

[39] Dixon, A. G., and Cresswell, D. L., 1979, "Theoretical Prediction of Effective Heat Transfer Parameters in Packed Beds," AIChE J., 25(4), pp. 663-676.

[40] Dekhtyar, R. A., Sikovsky, D. P., Gorine, A. V., and Mukhin, V. A., 2002, "Heat Transfer in a Packed Bed at Moderate Values of the Reynolds Number," High Temp., 40(5), pp. 693-700.
[41] Gunn, D. J., and Khalid, M., 1975, "Thermal Dispersion and Wall Heat Transfer in Packed Beds," Chem. Eng. Sci., 30, pp. 261-267.

[42] Delgado, J. M. P. Q., 2007, "Dispersion in Porous Media," Chem. Eng. Res. Des., 85(A9), pp. 1245-1252.

[43] Gunn, D. J., and de Souza, J. F. C., 1974, "Heat Transfer and Axial Dispersion in Packed Beds," Chem. Eng. Sci., 29, pp. 1363-1371.

[44] Clement, K., and Jorgensen, S. B., 1983, "Experimental Investigation of Axial and Radial Thermal Dispersion in a Packed Bed," Chem. Eng. Sci., 38(6), pp. 835-842.

[45] Levec, J., and Carbonell, R. G., 1985, "Longitudinal and Lateral Thermal Dispersion in Packed Beds," AIChE J., 31(4), pp. 591-602.

[46] Elsari, M., and Hughes, R., 2002, "Axial Effective Thermal Conductivities of Packed Beds,” Appl. Therm. Eng., 22, pp. 1969-1980.

[47] Yagi, S., Kunii, D., and Wakao, N., 1960, "Studies on Axial Effective Thermal Conductivities in Packed Beds," AIChE J., 6, pp. 543-546.

[48] Vortuba, J., Hlavacek, V., and Marek, M., 1972, "Packed Bed Axial Thermal Conductivity," Chem. Eng. Sci., 27, pp. 1845-1851.

[49] Vortmeyer, D., and Adam, W., 1984, "Steady-State Measurements and Analytical Correlations of Axial Effective Thermal Conductivities in Packed Beds at Low Gas Flow Rates," Int. J. Heat Mass Transfer, 27(9), pp. 1465-1472.

[50] Kunii, D., and Smith, J. M., 1961, "Heat Transfer Characteristics of Porous Rocks," AIChE J., 7, pp. 29-34.

[51] Metzger, T., Didierjean, S., and Maillet, D., 2004, "Optimal Experimental Estimation of Thermal Dispersion Coefficients in Porous Media," Int. J. Heat Mass Transfer, 47, pp. 3341-3353.

[52] Testu, A., Didierjean, S., Maillet, D., Moyne, C., and Niass, T., 2005, "Experimental Estimation of Thermal Dispersion Coefficients in Granular Media Through Which a Gas is Flowing: Porous Versus Nonporous Grain," Proceedings of the 5th International Conference on Inverse Problems in Engineering, Cambridge, UK.

[53] Testu, A., Didierjean, S., Maillet, D., Moyne, C., Metzger, T., and Niass, T. 2007, "Thermal Dispersion for Water or Air Flow Through a Bed of Glass Beads,” Int. J. Heat Mass Transfer, 50, pp. 1469-1484.

[54] Krupiczka, R., 1967, "Analysis of Thermal Conductivity in Granular Materials,” Int. Chem. Eng., 7, pp. 122-144. 